gegen die Lübecker Herren, insbesondere gegen Herrn Hagen, dem ortskundigen und liebenswürdigen Führer, schieden die Teilnehmer von einander.

Dr. O. Heinroth.

\title{
Beobachtungen bei einem Einbürgerungsversuch mit der Brautente (Lampronessa sponsa (L.)).
}

\author{
Von Dr. O. Heinroth.
}

(Hierzu Tafel I--IV).

Es ist ein knappes Vierteljahrhundert her, ich besuchte damals in Dresden die Unter-Sekunda, dafs ich, so oft es irgend meine freie Zeit erlaubte, in die dortige, unter dem Namen „Grofser Garten" bekannte, herrliche Königliche Parkanlage hinauszog, um die dort recht zahlreich vorkommenden Brautenten zu beobachten. Ursprünglich waren aus dem Dresdener Zoologischen Garten einige Stücke dieser Entenart, denen man wohl zur rechten Zeit die Flügel $\mathrm{zu}$ beschneiden vergessen hatte, nach den nahe gelegenen Teichanlagen des „Grofsen Gartens" geflogen, und dort hatten sich die Vögel in einigen Jahren recht zahlreich vermehrt, so dafs ich im Herbst des Jahres 1888 einmal 75 Stück auf und unter einer fruchttragenden Eiche versammelt sah. Da ich schon damals zu jeder Jahreszeit und zu jeder Tagesund Nachtstunde meine Beobachtungen angestellt hatte, so war ich als Abiturient des Gymnasiums mit den Lebensgewohnheiten von Lampronessa als wildem Parkvogel vollkommen vertraut, ein Umstand, der mir, als ich beinahe 20 Jahre später als Direktorial-Assistent des Berliner Zoologischen Gartens selbst Einbürgerungsversuche mit der Brautente machen konnte, sehr zu statten kam. Soviel stand nach meinen Erfahrungen bei mir fest, dafs die Verbreitung dieses Vogels über den benachbarten Tiergarten und andere Gewässer Berlins am besten in der Weise erfolgen müsse, dafs man im Zoologischen Garten erbrüteten und aufgezogenen Jungen nicht, wie es gewönlich geschieht, die Hand eines Flügels amputierte, sondern dafs man die jungen Enten sich einfach ganz selbst überläfst, indem man es ihnen freistellt, von ihren Flügeln Gebrauch zu machen, so viel sie wollen.

Es hat nun gewisse Schwierigkeiten, sich ohne wesentliche Kosten die nötige Anzahl von Enten heranzuziehen, denn wenn die Brautente auch unter recht ungünstigen äufseren Umständen verhältnismäfsig leicht zur Fortpflanzung schreitet, so hapert es doch im tiergärtnerischen Betriebe gewöhnlich mit dem Erfolge. Lä Ist man nämlich der alten Ente ihr Gelege, das sie, sogar im flugunfähigen Zustande, oft recht geschickt zu verbergen weifs, und erleidet die Brut auch wirklich nicht durch Ratten, Raubtiere oder den Strahl des Gartenschlauches ein tragisches Ende, so erscheint schliefslich die besorgte Mutter mit ihren munteren winzigen jungen Entchen. Aber was dann? Überläfst man die Familie ihrem 
Schicksal auf einem Teiche, auf dem noch andere Schwimmvögel gehalten werden, dessen Ufer künstlich befestigt sind, und in dem man mit Sicherheit darauf rechnen kann, dafs selbst nach genauester Untersuchung kein Wasserinsekt mehr zu finden ist, so sind die kleinen Dinger am dritten oder vierten Tage sämtlich verhungert. Ein Füttern der Jungen von Seiten des Menschen ist nämlich schlechterdings unmöglich, weil das andere Wassergeflügel sich sofort über einen derartigen Leckerbissen, wie es das Aufzuchtfutter ist, hermacht. Aufserdem pflegt die besorgte Mutterente ihre Jungen, wenn sich ein Mensch dem Teiche nähert, mit ängstlichen Rufen auf der entgegengesetzten Seite des Wasserspiegels $\mathrm{zu}$ versammeln.

Ich mufste also, um das nötige Material zum Freifliegenlassen $\mathrm{zu}$ erhalten, anders verfahren und mache dies im allgemeinen auch heute noch in folgender Weise: wenn ich merke, dafs ein Brautentenweibchen irgendwo zu legen anfängt, so störe ich es, bis die Zahl des Geleges mit 11 Eiern erfüllt ist, möglichst nicht. Da der Vogel an jedem Tage ein Ei legt, so brauche ich beispielsweise, wenn ich heute ein Nest mit 4 Eiern finde, erst nach weiteren 7 Tagen wieder nachzusehen; denn, störe ich $\mathrm{zu}$ oft, so ereignet sich es leicht, dafs die Ente ihr Nest aufgibt und die noch fälligen Eier anderswo ablegt. Das fertige Gelege wird der Ente dann genommen und einer geeigneten Haushenne gegeben, die dasselbe in dem gleichen Zeitraum wie die Ente, nämlich in 31 Tagen ausbrütet. Im allgemeinen macht dann die betreffende Ente nach einigen Wochen noch ein Gelege, das ich dann, wenn der Nestplatz günstig liegt, häufig von ihr selbst ausbrüten lasse. Im letzteren Falle pflege ich die jungen Enten ihrer Mutter möglichst einige Stunden nach dem Auskriechen wegzunehmen, um sie dann einer zuverlässigen Glucke, die auf den kleinen Dingern zunächst noch 24 Stunden ruhig sitzen mufs, zum Führen anzuvertrauen. Nicht jede Haushenne eignet sich dazu, junge Enten zu bemuttern, bei Kämpfer- und Phönixhennen, Jokohamas und anderen, dem wilden Gallus gallus noch näher stehenden Hühnern tritt häufig der Fall ein, dafs sie zwar auf Enteneiern ausgezeichnet brüten, die neugeborenen Enten aber sofort töten. Der „Führungsreflex" dieser Hühner wird durch den Anblick und die Stimme der Jungenten also nicht ausgelöst, im Gegenteil, sie halten die kleinen Dinger für eine zu bekämpfende „Nestgefahr."

Da die auskommenden jungen Brautenten, ebenso wie die meisten Wildenten, in der Freiheit zunächst fast ausschliefslich auf solche Insekten Jagd machen, die sich auf der Wasseroberfläche bewegen, so wollen sie häufig an die ihnen am 2. Tage-hingestreuten frischen Ameisenpuppen nicht recht heran, deshalb empfielt es sich, in den kleinen Raum, in den man die Henne mit ihren Pfleglingen steckt, einen flachen, mit Wasser gefüllten Blumentopfuntersatz zu stellen und auf diese kleine Wasserfläche 
einige frische Ameisenpuppen zu streuen, denn hier finden die jungen Enten dies vortreffliche Futter gewöhnlich sehr schnell, namentlich, wenn es sich bei ihrem Umherherschnattern auf dem Wasserspiegel bewegt. Später kann man die Ameisenpuppen auch wie üblich auf einem kleinen Brett reichen. Ist das Wetter nicht zu kalt und regnerisch, so gestattet man der ganzen Familie, sich auf möglichst kurz geschorenem Rasen $\mathrm{zu}$ tummeln, und gibt dabei den Jungenten Gelegenheit, in einem kleinen Wassergefäls zu schwimmen, welches man zu diesem Zweck am besten bis zu seinem oberen Rand in den Boden versenkt. Die munteren Dinger lernen es bald, auf der Grasfläche Fliegen und andere Insekten zu erhaschen und den Menschen als Futterspender zu schätzen. Nach einigen Wochen nehmen sie Spratts Patent „Kückenfutter“ gern an und gehen bald darauf auch an Körnernahrung. Für die Nacht wandern die Kleinen mit ihrer Pflegemutter in einen verschliefsbaren Kückenkasten oder einen ähnlichen Raum.

$\mathrm{Da}$ die jungen Brautenten gut zu Fufs sind, so kann man sie recht gut ohne einen Teich aufziehen: eine grofse Wanne, recht oft mit reinem Wasser gefüllt, genügt für ihre Badebedürfnisse. Im Alter von etwa 6 Wochen, häufig auch schon früher, hören die Entchen auf, sich um ihre Pflegemutter zu kümmern, man kann sie jetzt unbedenklich von der führenden Henne trẻnnen und $\mathrm{zu}$ anderen Enten auf ein gröfseres Gewässer setzen, sie finden sich dort gut zurecht und lernen es rasch, sich selbst Futter zu suchen, bezüglich den Futternapf aufzufinden. Im Alter von 9 Wochen sind die Vögel recht gut flugfähig und fangen nun an, umherzustreichen.

Das Haupterfordernis, diese schönen amerikanischen Enten in einer bestimmten Gegend einzubürgern, ist offenes Wasser auch bei strengster Kälte, denn wenn ihre Wohngewässer zu zufrieren anfangen, verlassen sie diese, wie es alle anderen Schwimmvögel auch tun. Selbst in sehr harten Wintern haben sich die Brautenten als durchaus wetterfest erwiesen, natürlich sind sie bei sehr hohen Kältegraden stiller, und die Beine frieren ihnen tüchtig, aber anscheinend nicht mehr als z. B. unserer Stockente (Anas boscas) auch.

Zweimal habe ich versucht, Brautenteneier durch wilde Stockenten ausbrüten und die Jungen aufziehen $\mathrm{zu}$ lassen, da ich glaubte, dafs ich auf diese Weise unter sachkundiger Führung eine recht weite Verbreitung der jungen Brautenten in die entferntere Umgebung erzielen würde. Es stellte sich nun heraus, dafs die Stockente die ihr untergelegten Brautenteneier zwar ohne Zögern annahm und glücklich ausbrütete, aber dann trat etwas ein, was ich nicht erwartet hatte. Im ersten Falle war an dem betreffenden Morgen, an welchem die jungen Brautenten fällig waren, die Ente einfach weggeflogen, und die jungen Brautenten irrten piepend und frierend auf dem ganzen Teiche herum, um bald ein klägliches Ende zu 
finden. Mit der zweiten Stockente ging es nicht viel besser. Hier konnte ich von einem geeigneten Standpunkte aus mit dem Fernglase das Nest gut beobachten und feststellen, dafs die brütende Ente von den auskommenden Jungen sehr wenig Notiz nahm. Sie safs zwar unruhig auf ihrem Neste, drehte sich oft im Kreise und sah unter sich, nach einer Weile jedoch war wieder Ruhe eingetreten, und die Alte brütete ruhig weiter. Bei näherem Zusehen fand sich nun, dafs die Stockente auf den leeren Eierschalen weiter brütete, ein Teil der jungen Brautenten hatte das Nest verlassen, und einige krabbelten noch am Rande desselben umher, ohne dafs die Brüterin ihnen irgend welche Aufmerksamkeit schenkte. Ich verjagte die Stockente vom Nest und entfernte die Eierschalen. Einige Brautentchen schlossen sich durch Zufall an die auf dem Wasser umherschwimmende Stockente an, diese tat ihnen auch nichts zu leide, kümmerte sich aber in keiner Weise um das kleine Volk, und am nächsten Tage konnte von den zahlreichen wolligen Dingern keines mehr aufgefunden werden. Es ergab sich also, dafs der „Führungsinstinkt" der brütenden Stockente durch die optischen und akustischen Eindrücke, welche von jungen Brautenten ausgehen, nicht erregt wird, und in der Tat sind hinsichtlich der Stimme und auch der Färbung des Dunenkleides die neugeborenen Lampronessa recht verschieden von den Jungen $A$. boscas. ${ }^{1}$ )

Nach diesen technischen und praktischen Fragen möchte ich im Folgenden ein Lebensbild der Brautente entwerfen, das bei genauerer Betrachtung doch etwas anders ausfällt, als es z. B. in "Brehms Tierleben" geschildert und von dort durch die gesamte Brautentenliteratur immer wieder abgeschrieben wird, auch die Angaben Gundlachs bedürfen namentlich hinsichtlich der Stimme unserer Vögel der Berichtigung.

Was zunächst die systematische Stellung der Brautoder Karolinenente betrifft, so wird sie als einzige Art der Gattung Lampronessa zugeteilt. Ihre allernächste Verwandte ist die nordostasiatische Mandarinente (Aix galericulata), die ja aber als Sondergattung von der Brautente abgetrennt ist. Wenn in der Handliste des britischen Vogel-Katalogs diese beiden Arten zusammen mit der Brasilianischen „Türkenente" (Cairina moschata), der riesigen Sporengans (Plectropterus) und anderen heterogenen Anseriformes der Unterfamilie der Plectropterinae zugeteilt werden, so glaube ich dieser Auffassung doch nicht beitreten $\mathrm{zu}$ können und sehe in Lampronessa und Aix einfach Gattungen der eigentlichen Schwimmenten, Anatinae, wobei ich

1) Anmerkung: Wie mir Herr Schwabe (Schlofsgut Seebach) mitteilt, kann man zahme Stockenten, die noch nie eigene Junge geführt haben (aber nur solche!), dadurch zum Bemuttern der von ihnen erbrüteten Brautenten bringen, dafs man sie mindestens 2 Tage lang ganz eng mit diesen zusammen einsperrt. 
allerdings betonen will, dafs Braut- uud Mandarinente unter sich viel näher verwandt sind, als jede der beiden Arten mit irgend einer anderen Schwimmentenform.

Einen recht guten Anhaltspunkt für die Blutsverwandtschaft verschiedener Arten haben wir nach Herrn Professor Poll in dem Grade der Fruchtbarkeit, bezüglich Unfruchtbarkeit, ihrer Mischlinge kennen gelernt. Während z. B. die in Stimme und Lebensgewohnheiten äufserst ähnlichen Anas-Arten A. boscas, superciliosa und poecilorhyncha sich ohne weiteres unter einander vermischen und auch weiterhin fruchtbare Bastarde ergeben, so sind z. B. die Hybriden der Gattung Dafila (Spiefsente) einerseits und Mareca (Pfeifente) andererseits vollkommen unfruchtbar, wie sich nach häufiger, histologischer Untersuchung der Genitalorgane der oft gezüchteten Mischlinge zwischen südamerikanischer Spiefsente (Dafila spinicauda) und Chili-Pfeifente (Mareca sibilatrix) ergeben bat. Herrn Professor Poll und mir lagen nun sowohl männliche als weibliche Bastarde zwischen Brautente einerseits, und Pfeifente (Mareca penelope), Tafelente (Aithya ferina) u. Peposakaente (Metopiana peposaca) andererseits vor, die sich sämtlich steril verhielten, und ich kannte aus meiner Schülerzeit her mehrere recht ansprechend gefärbte Stock-Brautentenmischlinge, die sich ebenfalls niemals fortpflanzten. Alles dies spricht für die exclusive Stellung der Gattung Lampronessa. Mischlinge zwischen Braut- und Mandarinenten werden in der Literatur erwähnt, es ist mir aber noch nicht gelungeu, einen solchen Hybriden zu Gesicht zu bekommen oder gar zu erzielen, trotzdem wir im Berliner Zoologischen Garten diese beiden Arten sowohl in der Volière, als auch völlig frei nebeneinander halten, ja ich habe bis jetzt noch nie bemerkt, dafs sie sich geschlechtlich für einander interessieren. Ein sehr bekannter süddeutscher Zierentenzüchter, Herr Samereier, sperrte auf meinen Wunsch einen Brauterpel mit einer Mandarinente, und in einem andern Abteil einen Mandarinerpel mit einer Brautente zusammen und machte die Erfabrung, dafs, obwohl sich die Tiere häufig begatteten, sämtliche Eier dieser beiden Weibchen unbefruchtet waren. Erst als der genannte Züchter aus den vier Vögeln wieder zwei artgleiche Paare machte, erhielt er befruchtete Eier. Nach diesen Erfahrungen scheint es mir doch, als wenn die Bastardierung von Braut- und Mandarinenten nicht so einfach ist, als man bei der Verwandtschaft dieser beiden Gattungen und namentlich bei der Ähnlichkeit der Weibchen beider Arten anzunehmen geneigt ist. Bekanntlich weichen Lampronessa und Aix von den übrigen Schwimmenten vor allen Dingen durch den verhältnismärsig recht langen und breiten Schwanz ab, und für beide charackteristisch ist die glänzend silberweifse Färbung der Aufsenfahne der Handschwingen: dieses Kennzeichen kommt keiner anderen Anatide zu, ist also für die Bestimmung dieser beiden Arten absolut zuverläfsig. Hier sei gleich erwähnt, dafs ein auch 
bei dem Jugend- und Weibchenkleid nie im Stich lassender Unterschied zwischen Braut- und Mandarinente darin besteht, dafs die Unterflügeldecken bezüglich Axillarfedern der ersten Art schwarzbraun und weifs quergestreift, also gesperbert sind, während diese Federn bei der Mandarinente einfarbig braun erscheinen.

Die Heimat der Brautente sind die Waldseen des gemälsigten Nordamerika, etwa vom Staate New York an bis nach Mexiko hinunter. Während des Winters streicht sie von den Nordstaaten aus ziemlich weit südlich nach Mittelamerika hinein, um dann im April wieder an ihren Brutpiätzen einzutreffen. Sie gilt in ihrer Heimat als wenig scheu, und zumal da der Schütze, durch Bäume gedeckt, gut an sein Wild herankommen kann, als leicht $\mathrm{zu}$ schiefsen. Sie scheint auch wenig Scheu vor menschlichen Niederlassungen zu haben, es kann daher nicht Wunder nehmen, dafs dieser herrliche Vogel in den bevölkerteren Gegenden ziemlich ausgerottet ist: ja lebende Stücke sind in den Vereinigten Staaten so teuer geworden, dafs die Amerikaner häufig lebende Brautenten aus Europa kaufen! Der Fang dieser Waldenten, der ,WouldDucks", geschieht in der Weise, dafs man auf treibenden Baumstämmen oder niedrigen, über den Wasserspiegel ragenden Ästen Schlingen legt.

\section{Äussere Kennzeichen, Tragfedern, Zeichnungsweise.}

Aus rein wissenschaftlichen Gefiederbeschreibungen ${ }^{1}$ ) wird der in solchen Dingen nicht sehr geübte Fachornithologe meist nicht recht klug, er kann sich wenigstens nach ihnen kein rechtes Gesamtbild des Vogels machen, und ich möchte daher auf die beigegebenen Bilder verweisen, um dem Leser eine Vorstellung von dem anmutigen Zeichnungsmuster der Brautente, insbesondere des Männchens im Prachtkleide, zu geben. Besonders auffallend sind bei letzterem aufser der fast einfarbig schwarzen, stahlblau glänzenden Oberseite, die scharfen weifsen Striche, die zum Teil, anscheinend $\mathrm{um}$ sie noch mehr hervortreten zu lassen, schwarz umrändert sind. Am meisten in die Augen fällt die weifse Linie, welche etwa hinter der Kropfgegend, ziemlich rechtwinklig zur Längsaxe des Körpers an der Seite des Vogels sich herunterzieht (s. Tafel I, Bild 2), und der beinahe lotrecht zu ihr stehende weifse Längsstreifen, welcher durch den oberen Rand der Tragfedern gebildet wird. Diese markante Zeichnung ist es, an der man den alten männlichen Vogel von etwa Mitte September bis zum Anfang des Juni auf grofse Entfernungen hin erkennt, selbst wenn er, wie er es zu tun liebt, in den Mittagsstunden sich zum Schlafen unter dichtes Ufergebüsch zurückgezogen hat.

Bei dieser Gelegenheit möchte ich auf die sogenannten Trag f e d e r $n$ und ihre Bedeutung etwas näher eingehen. Man versteht

1) Diese s. am Schlusse dieses Aufsatzes. 
darunter diejenigen Seitenfedern, welche die Unterseite des Vogels nach den Flügeln hin begrenzen. Sie sind meist ziemlich grofs und liegen, nicht wie es bei ausgestopften Vögeln und bei Zeichnungen, - so z. B. in „Brehms Tierleben“" noch in der IIl. Auflage! meist ganz verkehrt dargestellt wird, der Längsachse des Körpers parallel, sondern sie biegen sich beinahe rechtwinklig nach oben und bilden somit eine Tasche, in welcher für gewöhnlich der geschlossene Flügel ruht. So kommt es, dafs man z. B. bei einer schwimmenden Ente von dem Flügel, aufser vielleicht von der Flügelspitze und den innersten grofsen Armschwingen, überhaupt nichts sieht. Namentlich bei Tauchenten fällt dies ganz besonders auf.

Gerade beim Brauterpel, bei dem ja die Tragfedern durch ihre prächtige Färbung so besonders auffallen, lassen sich diese Verhältnisse besonders schön studieren. (Siehe Tafel I, Bild 1). Die Tragfedern fixieren den Flügel in der Ruhelage und schützen ihn vor allen Dingen vor der Berührung mit Wasser. Der Körper der schwimmenden Ente liegt gleichsam in einem Federkahn, dessen Bordwand eben durch die Tragfedern gebildet wird. Jeder von uns hat wohl schon beobachtet, wie Gänse und Enten sich über den Wasserspiegel aufrichten, mit den Flügeln schlagen und den zusammengelegten Fittich dann wieder unter die Tragfedern stecken, und diese Bewegungen werden von Gänsen, Enten, Schwänen und Sägern reflektorisch stets dann ausgeführt, wenn die Unterseite des Flügels oder die Innenseite der Tragfedern mit Wasser in Berührung gekommen ist, sie dienen also, wenigstens häufig, dazu diese Teile zu trocknen. Wie reflektorisch diese Bewegungsweise vor sich geht, davon konnte ich mich bei einer flügellos geborenen Hausgans überzeugen: wenn sie ins Wasser sprang und dabei von dem aufspritzenden Wasser ihre Oberseite bezüglich der obere Rand der Tragfedern benetzt wurde, so richtete sie sich jedesmal im Wasser hoch auf, und man konnte an dem Zucken der Brustmuskulatur sehr deutlich erkennen, wie das Tier ,mit den Flügeln schlug, die es nicht hatte". Gerade die Tragfedern sind es, welche ihrem Besitzer die Fähigkeit verleihen, lange auf dem Wasserspiegel zu verweilen und dort der Ruhe zu pflegen, wie es ja auch die meisten Anseriformes und auch die eigentlichen Möwen ${ }^{1}$ ) in der Gewohnheit haben. Den Ruderfüfslern, von denen wir die Pelikane und Scharben ja oft in der Gefangenschaft beobachten können, fehlen die Tragfedern, wenigstens in ihrer Eigenschaft als Flügeletuie, und diese Vögel haben daher eine ganz andere Schwimmweise. Der Pelikan, wenn er auch vermöge seines ungemein ausgebildeten Luftpolsters nur ganz wenig ins Wasser einsinkt, mufs trotzdem die Flügel dauernd etwas anheben, um sie vor Durchnässung zu nie! (H.)

1) Seeschwalben haben keine eigentlichen Tragfedern und schwimmen 
schützen. Beim Kormoran und Schlangenhalsvogel werden die Schwingen beim Aufenthalt des Vogels auf und unter dem Wasser nur lose seitlich neben dem Körper getragen, sie kommen dauernd mit dem Wasser in Berührung, und das Tier mufs, wie bekannt, so wie es ans Land kommt, lange Zeit für das Trocknen seiner Schwingen sorgen, indem es diese in weit geöffnetem Zustande viertelstundenlang fächelnd hin und her bewegt. Keine Scharbe ruht auf dem Wasser nach Entenart, sie besucht dasselbe nur des Nahrungserwerbes wegen und mufs immer wieder bald das Trockene aufsuchen: gerade hierdurch wird die grofse physiologische Bedeutung der Tragfedern für die anderen Schwimmvögel am besten klar. Wie schon erwähnt, sind diese Federgebilde bei den Tauchenten am vollkommensten entwickelt. Bei diesen wird der an sich schon recht kleine Flügel auch un ter Wasser vollkommen wasserdicht abgeschlossen, sodafs eine auf dem Grunde des Gewässers nahrungsuchende Tauchente bei ihrem jedesmaligen Auftauchen keine Zeit auf die Ordnung und Trocknung ihres Gefieders zu verwenden braucht. Taucht dagegen eine Schwimmente oder eine Gans, so dringt ihr jedesmal Wasser unter die Tragfedern, und wir sehen denn auch, dafs diese Vögel, sobald sie wieder an der Oberfläche erscheinen, nach einigen kurzen Badebewegungen das anfangs erwähnte Flügelschlagen nötig haben. Mischlinge von Tauch- und Schwimmenten verhalten sich so, dafs dieses Gefiederordnen je nach mehrmaligem Untertauchen bewerkstelligt werden mufs.

Beachten wir die Zeichnungsweise des Brauterpels genauer, so werden wir finden, dafs bei dem Kopf- und Halsgefieder die weifsen und schwarzglänzenden Teile je weifsen und schwarzglänzenden Federn entsprechen, bei dem weifsen Strich jedoch, welcher die Kropfseite begrenzt, verhält sich die Sache anders. Hier haben, von vorn nach hinten gerechnet, zunächst die braunen Federn weifse Spitzen. Letztere werden bei den folgenden Federn immer breiter, dann kommen solche Federn, bei denen auf ein breites weifses Band eine schwarze Spitze folgt, und die dann folgenden sind schwarz, mit einem feinen Querstrich vor den schwarzen Endteilen. Auf ganz ähnliche Weise kommt z. B. auch das weifse Halsband des Stockerpels zustande. Auch hier kommen zunächst grüne Federn mit weifsen Spitzen, dann weifse Federn und schliefslich weifse Federn mit brauner Spitze: kurzum bei sehr vielen Zeichnungsmustern hat man das Gefühl, als sei gewissermafsen auf das fertige Gefieder die Farbe von aufsen aufgetragen.

Es ist vielleicht nicht uninteressant, mit einigen Worten auf


Weibchen einzugehen. Während die Handschwingen und das kleine Gefieder des Flügels bis auf die beim Weibchen schöner gefärbten grofsen Armdecken im wesentlichen bei beiden Geschlechtern gleich sind, so sind die Armschwingen, also Spiegel- 
federn des Erpels auf der Aufsenfahne prachtvoll stahlblau und zeigen ein schmales weifses, ca. $2-3 \mathrm{~mm}$ breites Spitzenband, vor dem noch eine schwarze Linie vorbeizieht. Bei dem weiblichen Vogel ist der Spiegel auffallender gefärbt, d. h. an Stelle des schmalen weifsen Endbandes des Erpels finden wir hier grofse, an der breitesten Stelle $8 \mathrm{~mm}$ messende halbmondförmige weifse Flecke. Die vier innersten Armschwingen zeigen beim Erpel manche Besonderheiten. Die Vierte, welche ich als „Messingfeder" bezeichnen möchte, zeigt an ihrer Aufsenfahne einen leuchtenden bronze- bis messingartigen Glanz, ihr fehlt auch der weifse Endrand. Die drittinnerste Armschwinge, die eine wesentlich andere Form als die übrigen aufweist und vor allen Dingen viel breiter ist, zeigt ein prächtiges stahlglänzendes Schwarz mit weifsem, ganz fein schwarz begrenztem Endsaum, und diese Feder ist es, welche beim geschlossenen Flügel denjenigen weifsen Strich bildet, der den breiten weifsen, durch die Aufsenfahnen der Handschwingen gebildeten Längsstreifen unmittelbar hinter und über den Tragfedern in so ansprechender Weise zum Abschlufs bringt. Die beiden innersten Armschwingen endlich sind ebenfalls breiter und einfarbig glänzend schwarz.

Die Färbung von Auge und Schnabel ist je nach der Jahreszeit einem Wechsel unterworfen. Die Iris ist, namentlich im Frühling prachtvoll und leuchtend karminrot, nach aufsen hin häufig etwas brä̉unlich gefärbt, und dieses Braun verbreitet sich während der Mauserzeit und in den Sommermonaten fast über die ganze Regenbogenhaut, sodafs der Gesichtsausdruck des Tieres dann viel matter und unscheinbarer wird. Der Lidrand ist ebenfalls rot, am vorderen Rande verbreitert sich dieser Farbenrand ein wenig. Die Färbung des Schnabels zeigt im Frühjahr oben, unmittelbar an der Wurzel, einen schmalen, intensiv gelben Rand, auf den eine im Mittel etwa $8 \mathrm{~mm}$ breite, dunkel karminrote Zone folgt, die sich nach vorn als feine Linie an den Oberschnabelrändern hinzieht. Die Schnabelspitze auf etwa $14 \mathrm{~mm}$, sowie ein etwa $22 \mathrm{~mm}$ langer und $10 \mathrm{~mm}$ breiter Streifen auf der Oberkante des Schnabels zwischen den Naslöchern sind schwarz, der übrige Teil ist weifslich. Nach Beendigung der Paarungszeit werden diese Prachtfarben recht unscheinbar, insbesondere macht das schöne Karminrot einem schmutzigen Blaurot Platz. Setzt man jedoch einen solchen Vogel hoher Temperatur aus, oder sperrt man mehrere Stücke, was auf dasselbe herauskommt, in einen engen Kasten, so dafs die Tiere recht heifs werden, so tritt das leuchtende Schnabelrot sofort wieder zu Tage. Es scheint also, dafs diese Farbe lediglich eine Folge von starker Blutdurchströmung der betreffenden Schnabelpartie ist.

Bei dem an sich unscheinbaren Kleide des Weibchens ist das Auffallendste die weifse Brillenzeichnung um die Augen und der feine weifse Rand um den Schnabel (s. Tafel I, Bild 3 und 7). Diese Gesichtszeichnung ist es, an der man die weibliche 
Brautente auf grofse Entfernungen hin auffindet, denn das übrige Gefieder geht so in die Bodenfarbe über, dafs der Vogel schon in der Nähe, namentlich im dürren Laub, Gras u. s. w., unsichtbar wird, und in der Schlafstellung, das heifst also, wenn der Vogel seinen Schnabel unter die Schulterfedern gesteckt hat, sind die Weibchen sehr schwer zu finden. Auch sie haben die weifse Flügelzeichnung, nämlich in der Ruhelage des Flügels das breite, weifse, durch die Aufsenfahne der Handschwingen bedingte Längsband, das nach dem Rücken zu und nach vorn seinen Abschlufs durch eine weifse Querlinie findet. Letztere wird nun auffallender Weise nicht wie beim Erpel durch den weifsen Rand einer verbreiterten, inneren Armschwinge gebildet, sondern die bei der Ente, wie schon erwähnt, auf den meisten Armschwingen vorhandenen breiten, weifsen, halbmondförmigen Endflecke erzeugen im zusammengelegten Flügel diese Zeichnungsweise. Beim Weibchen ist auch die vorherbeschriebene Messingfeder des Erpels kaum durch ihre Färbung angedeutet, und die innerste Armschwinge entspricht vollkommen in ihrer Färbungsweise dem Rückengefieder ihrer Trägerin. Letzteres ist, im Gegensatz zu dem der Weibchen aller europäischen Schwimmenten, so gut wie einfarbig. Der Lidrand der Ente ist gelb bis orangegelb, das Auge dunkelbraun.

Das Da unenkleid der Brautente (S. Tafel III, Bild 2) zeigt in seinem ganzen Färbungscharakter manche Ähnlichkeit mit dem verschiedener anderen Schwimmenten. Ganz charackteristisch ist die Kopfzeichnung insofern, als ein eigentlicher schwarzer Zügelstrich fehlt, nur seine Fortsetzung hinter den Augen an den Schläfen entlang ist sehr stark und deutlich ausgeprägt. Das erste Federkleid (S. Tafel III, Bild 4) ähnelt bis $\mathrm{zu}$ einem gewissen Grade dem Kleide des Weibchens oder auch dem Sommerkleide des Erpels, nur sind die Farben an Kopf und Hals noch weniger abgesetzt und ausgeprägt, auch ist an den Tragfedern nicht die starke weifsgelbe Fleckung des Weibchenkleides vorhanden, sondern sie ist nur schwach angedeutet. Bereits in diesem Stadium sind Erpel und Ente leicht $\mathrm{zu}$ unterscheiden. Die Seitenfleckung ist beim Weibchen etwas kräftiger, alle für den Flügelspiegel charakteristischen Einzelheiten sind auch im Jugendkleide bereits vorhanden, und das junge Männchen zeigt recht gut, wenn auch nur andeutungsweise, das Kopfzeichnungsmuster des erwachsenen Männchens, insbesondere ist der weifse Strich, welcher hinter den Augen rechtwinkelig nach abwärts führt, gut zu erkennen.

Das So m merkleid (S.Tafel IV, Bild 3) des Erpels, welches fast genau währenddes Kalendersommers getragen wird, ist ziemlich einfarbig. Nur die Flügel, die in der Hauptsache nur einmal im Jahre vermausert werden, haben bis auf die 3 innersten Armschwingen natürlich dieselbe Färbung wie im Prachtkleide, und das Kopfkleingefieder entpricht letzterem in seinem Zeichnungsmuster ziemlich genau, nur 
dafs statt der glänzend gefärbten Federn bräunliche vorhanden sind, aufserdem fehlt die Haube. An dieser stets gleichbleibenden Kopfzeichnung ist der Brauterpel in allen Kleidern leicht zu kennen, ganz im Gegensatz zu dem Männchen der Mandarinente, das im Sommerkleid seine für das Prachtkleid so charakteristische Kopfzeichnung gänzlich verliert und im ganzen Kleingefieder dem Weibchen absolut gleicht.

Hinsichtlich der Körpergrö fse kommt die Brautente der Pfeifente (M. penelope) am nächsten, ist aber ein wenig kleiner.

\section{Mauser.}

Der Frsatz der Federn findet stets aus derselben Papille statt, von welcher auch die ausfallende Feder erzeugt war. Man kann sich von dieser Tatsache leicht überzeugen, wenn man eine Feder einige Tage vor ihrem natürlichen Ausfall auszieht, dann sitzt an ihrer Basis der wenige $\mathrm{mm}$ lange Keim der nachfolgenden Feder, so dafs es für den Uneingeweihten leicht den Eindruck macht, als habe die alte Feder noch einen Blutkiel. Es ist immerhin erstaunlich, dafs die Papille $\mathrm{zu}$ verschiedenen Jahreszeiten ein so sehr verschieden gefärbtes Gebilde hervorbringen kann: man denke z. B. beim Brauterpel an die im Sommerkleid kurzen und unscheinbaren, im Prachtkleid dagegen stark verlängerten und buntgefärbten Kopffedern.

Als bekannt darf ich wohl voraussetzen, dafs alle Farbenveränderungen, also Übergänge von einem Kleid ins andere, s tets nur durch Mauser, niemals aber durch s.ogenannte „Verfärbung“ zu Stande kommen wie man sich leicht überzeugen kann, wenn man einen Erpel, der sich im Übergangskleide befindet, in die Hand nimmt. Denn während alle alten Federn verhornt sind, und bei der Berührung sehr leicht ausfallen, finden sich frische Blutkielfedern an den Stellen, an welchen das neue Kleid bereits zu Tage tritt. Bei dem Übergang vom Jugend- ins Alterskleid, sowie vom Sommerins Prachtkleid, wird das gesamte kleine Gefieder und die Steuerfedern vermausert, nur die 40 Schwingen und deren gröfste Deckfedern werden nicht gewechselt. Wir haben, und dies gilt für alle von mir beobachteten eigentlichen Enten, mit Ausnahme einiger tropischer Formen, denen ein Sommerkleid fehlt, also folgende Kleider zu unterscheiden:

1. Dunenkleid. Dieses ist fertig vorhanden, wenn der Vogel die Eischale verlälst, jede einzelne Daune ist aber mit einer feinen Hülle (s. Tafel III, auf Bild 2 die Hüllen noch spurweise vorhanden) umgeben, die nach dem Eintrocknen leicht abfällt, sodals das fertige Dunenkleid erst durch Abreiben dieser Hüllen bei den Bewegungen der Jungen untereinander und an der Brust der Mutter innerhalb des Nestes seine definitive Ausbildung erlangt. Dies ungemein dichte Primärgefieder 
befähigt die Jungen, bereits im Alter von wenigen Stunden das Wasser aufzusuchen, ohne dafs ihr Körper benetzt wird.

2. Jugendkleid. Im Alter von etwa 4 Wochen bemerkt man bei äufserlicher Betrachtung die ersten wirklichen Federn und zwar namentlich in der Schultergegend und an den Brustseiten zwischen den Primärdaunen hervorsprossen, bis endlich, wenn die Ente 7-8 Wochen alt geworden ist, nur noch ein kleiner Dunenrest sichtbar ist (s. Tafel III, auf Bild 4 letzte Daunen in der Nackengegend erkennbar). Auch kann man beobachten, dafs die alten Daunen zunächst noch an den Spitzen der Jugendfedern sitzen bleiben, erst allmählich gehen sie durch Abreiben, Wind u. s. w. verloren. Wie bei allen Zahnschnäblern erscheinen die Schwingen verhältnismäfsig spät, man miöchte sagen, der ganze Flügel fängt überhaupt erst an zu wachsen (s. Tafel III, Bild 3), wenn die junge Ente 4 Wochen alt ist, ja, bei den Tauchenten verzögert sich der Beginn des Flügelwachstums noch um einige Wochen mehr. Etwa mit Beendigung der 9. Lebenswoche sind junge Brautenten flugfähig, die Schwingen sind zu dieser Zeit aber noch nicht voll erwachsen, und die Tiere unternehmen noch keine gröfseren Ausflüge. Wie schon erwähnt, sind die Geschlechter an der Zeichnung der Armschwingen und noch früher an der des Kopfes in diesem Kleide leicht zu unterscheiden. Bis zum Alter von 3 Monaten sieht man aufser einer geringen Gröfsenzunahme keine weitere Veränderung.

3. Nach Ablauf dieser Zeit jedoch beginnt allmählich die Mauser ins A l t ers kl eid, von der nur die eigentlichen 40 Schwungfedern und deren gröfste Decken ausgeschlossen sind. Der junge Erpel ist mit etwa $4^{1} / 2$ Monaten äufserlich betrachtet im Besitzeseines vollen Prachtkleides, die Ente hat ins definitive Weibchenkleid gemausert, und es hält dann nicht ganz leicht, die jungen Vögel von mehrjährigen $\mathrm{zu}$ unterscheiden. Der Erpel trägt sein Prachtkleid bis etwa gegen Ende des Mai und legt, einige Zeit vor Beginn seiner Flugunfähigkeit, das unscheinbare.

4. Sommerkleid an, wird dann etwa Mitte Juni flugunfähig, beginnt Ende Juli, nachdem er eben wieder fliegen kann, mit der Mauser ins Prachtkleid, und ist zu Anfang, bezüglich Mitte September ziemlich vollständig wieder in Pracht.1) Junge Erpel legen das Prachtkleid später an, als der alte Vogel, sodals sie also zum Herbstbeginn noch nicht ausgefärbt sind. Der Eintritt der Mauser richtet sich bei jungen Tieren nach dem Lebensalter

1) Vergl. 0. Heinroth „Beobachtungen über die Schnelligkeit des Federwachstums". Ornithol. Monatsberichte 1906 Jahrg. XIV, No. 7/8. Nach meinen Beobachtungen beträgt das Wachstum der längsten Schwingen im allgemeiuen $7 \mathrm{~mm}$ pro Tag, ganz im Anfang und am Ende ist das Wachstum etwas verlangsamt. Ersetzte ausgerissene Federn, deren Hervorsprossen gew ohnlich erst nach 14 Tagen bis 3 Wochen beginnt, haben eine etwas geringere Wachstumsgeschwindigkeit. 
der einzelnen Stücke, sodafs also die einer Maibrut entstammenden Vögel sich schon zum Oktober hin ausfärben, während im Juli ausgekommene Junge erst $\mathrm{zu}$ Ende des Herbstes ihr volles Prachtkleid angelegt haben. Bei älteren Tieren richten sich die Umfärbungstermine nach der Jahreszeit, nicht aber nach dem individuellen Lebensalter, sodafs sich bei diesen die Mauserzeiten recht gleichmäfsig gestalten: sie entsprechen fast genau denjenigen unserer Stockenten, liegen aber im Durchschnitt um einige Tage früher. Es sei noch erwähnt, dafs jede Verschlechterung der Konstitution eines einzelnen Tieres eine Verzögerung im Mausertermine mit sich bringt. So sind z. B. alle in einer Volière des Berliner Zoologischen Gartens gehaltenen Brautenten mit dem Anlegen des Sommer- und Prachtkleides ihren freilebenden Genossen gegenüber um etwa einen Monat im Rückstande.

Bekanntlich wird der $\mathrm{Z}$ weck des Sommerkleides dahin gedeutet, dafs es den Träger für die fatale Zeit der Schwingenmauser, welche ihn auf etwa 5 Wochen flugunfähig macht, den Blicken seiner Feinde möglichst entziehen soll. In der Tat findet das Abwerfen der grofsen Flügelfedern zu dem Zeitpunkte statt, wenn das Sommerkleid, wenigstens äufserlich betrachtet, ziemlich fertig angelegt, also von den leuchtenden Farben des Erpels nichts mehr sichtbar ist. Sobald die Schwingen erwachsen sind, beginnt die Mauser vom Sommer- ins Prachtkleid.

Die charakteristische Schnabelfärbung erscheint etwa in der Zeit, zu welcher der junge Erpel sein erstes Prachtkleid anlegt.

5. W eib ch en kleid. Die weibliche Ente mausert nur einmal jährlich und zwar das gesamte Gefieder, wobei auch sie flugunfähig wird. Der Federwechsel tritt bei ihr später ein als beim Erpel, etwa im August, und steht in einer gewissen Abhängigkeit zum Fortpflanzungsgeschäft. Normalerweise verliert die Entenmutter die Schwingen, wenn ihre Jungen schon ziemlich herangewachsen sind und die Brutpflege also allmählig einzuschlafen beginnt, dies tritt für gewöhnlich etwa Mitte Juli ein. Zwingt man die Ente durch Wegnahme des ersten oder selbst des zweiten Geleges zu einer sehr späten Brut, so rückt auch der Mauserbeginn immer weiter hinaus.

Auch bei der Brautente bilden sich an solchen Körperstellen, die Verletzungen ausgesetzt waren, häufig weifse Federn. So hatten einige Weibchen auf der Frühlingsnestsuche das Unglück, in einen Schornstein zu geraten, aus dem sie sich nicht wieder herausarbeiten konnten. Einige fanden dabei ein tragisches Ende, einige wurden durch Zufall gerettet, waren aber nicht nur vollkommen ermattet und über und über berufst, sondern wiesen zum Teil auch Verbrennungen am Schnabel, im Gesicht und an den Flügelspitzen auf. Diese "Schornsteinenten" sind auch noch nach mehrmaliger Mauser an ihrem weifsfleckigen Gesicht, und an dem zum Teil oder ganz weifsgefärbten Schnabel zu erkennen. (Siehe Tafel I, Bild 2.) 


\section{Tägliche Lebensgewohnheiten.}

Wie die meisten Enten, ist auch die Brautente in den Morgen- und Abendstunden am lebhaftesten. Um diese Zeit streicht sie umher, geht auf Nahrungssuche aus und knüpft Bekanntschaften mit anderen Artgenossen an. Die verhältnismäfsig grofsen Augen deuten schon darauf hin, dafs unser Vogel auch im Halbdunkel gut sehen kann, und durch sie wird es der Ente ermöglicht, auch bei schon recht vorgeschrittener Dunkelheit durch das Geäst des Waldes zu fliegen. Es sei hier erwähnt, dafs die nahe verwandte Mandarinente in noch ausgesprochenerer Weise Dämmerungstier ist, ein Umstand, der ihren Wert als Parkvogel ziemlich erheblich beeinträchtigt: denn sie hält sich am Tage fast vollkommen versteckt, um erst, wenn die Nacht schon hereinbricht, auf der Wasserfläche zu erscheinen, sodafs man nur selten Gelegenheit hat, die eigenartige Schönheit dieser Ente zu geniefsen.

In den späteren Vormittagsstunden wird nach Entenart der Ruhe gepflegt, d. h., auf einem Bein stehend mit unter die Schulterfedern gestecktem Schnabel, unter einem Busch am Ufer, auf einem über den Wasserspiegel ragenden Ast, einem schwimmenden Baumstamm u. s. w. geschlafen. In der Zeit von 11-1 Uhr mittags wird nach Anatidensitte ein Bad genommen, und es ist merkwürdig, wie sehr sich alle Gänse, Enteú und Schwäne darin gleichen, dafs sie die Mittagszeit als Toilettenstunde angesetzt haben. Wie bei allen Zahnschnäblern geht dem eigentlichen Baden das bekannte "spielende Jagen" voraus. Es werden alle die Künste geübt, welche bei der Flucht vor einem Feinde für unsere Schwimmvögel nötig sind. Die Tiere fliegen dann plötzlich über das Wasser, tauchen im Augenblick des Einfallens unter, schwimmen weite Strecken unter dem Wasserspiegel hin und paddeln, als seien sie von einem unsichtbaren Feinde verfolgt, mit den Flügeln auf dem Wasser. Dieses zunächst von wenigen Exemplaren ausgeübte Spiel wirkt gewöhnlich ansteckend auf die meisten anwesenden Ordnungsverwandten, und es sieht dann geradezu aus, als seien sämtliche Teichgenossen plötzlich verrückt geworden. Schon ganz junge Enten betreiben dasselbe Spiel, auch ohne es je vorher von anderen Gattungsgenossen kennen gelernt zu haben, und ich habe es bei Jungenten gesehen, die nach Vollendung ihres ersten Lebenstages erst wenige Minuten auf dem Wasser waren, ohne dafs die Mutter ihnen etwa diese Spielbewegungen vorgemacht hatte. Da, wie anfangs erwähnt, es alle Zahnschnäbler für gewöhnlich ängstlich vermeiden, die Flügel und Innenseite der Tragfedern zu benetzen, denñ sie müssen ja dann immer erst wieder „Toilette machen", so hat es bei den erwähnten Spielen für uns Menschen geradezu den Anschein, als gingen die flatternden und tauchenden Enten von der Überlegung aus: „Jetzt können wir uns die Flügel tüchtig 
nafs machen, denn nachher putzen und baden wir uns ja so wie so!" Hierauf wird das eigentliche Bad genommen und dann ans Land gerudert. Man schüttelt sich tüchtig, schlägt mit den Flügeln, sucht sich in jeder Weise von dem anhaftenden Wasser zu befreien und fettet sich gründlich aus der Bürzeldrüse ein. Gewöhnlich reiht sich an diese Tätigkeit wieder ein Schläfchen, und die Nachmittagsstunden werden dazu verwandt, gemütlich am Ufer herumzusuchen. Bei eintretender Dämmerung wird die ganze Gesellschaft rege. Einzelne Paare erheben sich, kreisen umher, und streichen andern Gewässern $\mathrm{zu}$, und schliefslich folgen ganze Trupps diesem Beispiele. Inzwischen hat die Helligkeit so weit abgenommen, dafs der Beobachter Schwierigkeiten hat, die einzelnen Vögel zu erkennen, man hört aber an den Stimmäufserungen, wie regsam unsere Enten sind. Gern überfliegen zur Abendzeit verschiedene Paare die Umfassungsgitter der Teiche in unserem Zoologischen Garten, um sich zur Würmersuche auf die Wege und Rasenflächen $\mathrm{zu}$ begeben.

Natürlich werden diese täglichen Lebensgewohnheiten durch die verschiedene Länge der Tage im Sommer und Winter, durch die Mauser- und Fortpflanzungszeit entsprechend abgeändert. Auch die Witterung hat ihren Einflufs auf das tägliche Leben der Brautente. Man kann z. B. ein reges Umherfliegen noch in den späteren Morgen- und ersten Vormittagsstunden beobachten, wenn in der Frühe dauernder Regen herrschte oder dichter Nebel die Landschaft einhüllte: beides Erscheinungen, welche unsere Vögel in ihrem Umherstreifen hindern.

Es ist vielleicht bekannt, aber noch nicht darauf hingewiesen, dal's sich die Zahnschnäbler nicht nach Art der meisten Landvögel ,sonnen“, indem sie das Gefieder, Flügel und Schwanz ausbreiten, um sich so, wie wir es z. B. bei Hühnern, Singvögeln und anderen sehen können, mit wahrem Behagen den wärmenden Strahlen des Tagesgestirns hinzugeben. Die Entenvögel beschränken sich höchstens darauf, ein sonniges Uferplätzchen aufzusuchen, sie haben aber keine besondere Stellung der Gliedmafsen oder Federn für das sogenannte, sich Sonnen“.

\section{Bewegungsweisen.}

Der Gang der Brautente ist verhältnifsmäfsig gut und ausdauernd. Er erinnert wohl am meisten an die entsprechende Bewegung der Pfeifente ( $M$. penelope), ist aber zierlicher und von ähnlichem Kopfnicken begleitet, wie wir es von den Tauben her zu sehen gewohnt sind, nur ist die Kopfbewegung viel langsamer und erfolgt nicht bei jedem einzelnen Schritte. Sehr berechtigt erscheint mir gerade in unserem Falle die Annahme, dafs die Vögel im Gehen auf diese Weise die Augen immer auf kurze Zeit ruhig stellen, um dadurch deutlicheres Sehen zu ermöglichen: der Kopf wird schnell nach vorwärts genommen, bleibt ein Weilchen ruhig 
stehen, und der Körper geht inzwischen unter ihm ein Stück weiter. (Bei im Vorwärtsschreiten sichernden Wildgänsen werden diese Verhältnisse besonders deutlich.) Die Tiere tragen im Gehen den Körper sehr wagerecht und den Schwanz häufig verhältnismäfsig hoch: auch für ganz junge, erst wenige Tage alte Brautenten ist diese Haltung sehr charakteristisch, und sie verleiht ihrer Figur, von der Seite gesehen, etwas eigenartig Kahnförmiges. Auf der Suche nach Eicheln, Würmern, Insekten u. s. w. unternehmen unsere Brautenten namentlich in der Dämmerungsund Nachtzeit bisweilen weite Fufswanderungen. Bei der Nestsuche auf Bäumen sind sie häufig gezwungen, sich auch im Geäst zu Fufse zu bewegen, und weun man auch nicht sagen kann, dafs sie dabei gerade geschickt verfahren, so können sie dies doch viel besser, als solche Entenarten, die ihren natürlichen Lebensgewohnheiten nach niemals auf Bäume gehen. Die sehr scharfen Krallen befähigen unsere Vögel, sich an rauhen Wänden anzuklammern, also auch an einem schrägen, dicken Ast ohne $\mathrm{Zu}$ hilfenahme der Flügel in die Höhe zu laufen. Bei einer beabsichtigten Ortsveränderung von einem Zweig zum andern müssen die Tiere natürlich stets fliegen: von irgend welchem Hüpfen oder Springen kann dabei keine Rede sein. Aber gerade dieses Fliegen auf kurze Strecken und das sichere Treffen eines dünnen Zweiges ist für die meisten Zahnschnäbler ungemein schwer: man beobachte z. B. einmal, wie ungeschickt sich eine Stockente im Vergleich zu Lampronessa in dieser Lage anstellt. Beim Sitzen auf sehr dünnen Gegenständen, z. B. auf nur bleistiftstarken Ästen, werden diese natürlich nicht mit den Zehen umklammert, sondern die Tiere stehen, in geschickter Weise das Gleichgewicht haltend, mit nur schwach gekrümmten „Sohlen" auf einer solchen Unterlage, selbstverständlich bevorzugen sie aber, wenn angängig, stets dicke Äste vor solchen ihnen unbequemen, dünnen Zweigen. Über die Art, wie die ganz jungen Tiere ihre Krallen als Kletterorgane benutzen, soll unter der hubrik ,Fortpflanzung“ weiter die Rede sein.

Im Schwimmen ähnelt die Brautente durchaus den übrigen Schwimmenten, nur dafs bei besonderer Erregung häufig der Schwanz recht hoch getragen wird. Bisweilen kommt es auch vor, dafs unser Vogel die Steuerfedern im Wasser nachschleppt: dies scheint mir meist ein Zeichen von etwas geminderter Körperenergie $\mathrm{zu}$ sein, denn man sieht es manchmal an recht kalten Wintertagen bei beiden Geschlechtern und bei den Weibchen nicht ganz selten in der Legezeit.

Bis jetzt habe ich von den Anseriformes nur den Höckerschwan ( $C$. olor) nicht tauchen sehen, sonst wird diese Bewegung von allen Familienverwandten während des Spielens vor dem Baden (siehe oben) oder im Ernstfalle auf der Flucht ausgeführt. Die eigentlichen Enten (und Säger) verschwinden aufserdem noch von der Wasseroberfläche, um Nahrung vom 
Grunde des Gewässers heraufzuholen, und zwar tun dies nicht nur die Tauchenten, sondern auch viele Schwimmenten, wenn auch natürlich bedeutend seltener. Besonders zur Eichelzeit sieht man Stock-, Mandarin- und Brautenten täglich die ins Wasser gefallenen Eicheln vom Grunde heraufholen, und sie tauchen dann oft so emsig, dafs das früher erwähnte Flügelschlagen zwischen jedem Erscheinen an der Oberfläche ausbleiben kann.

Im Fluge hat die Brautente vor unseren heimischen Entenarten manches Eigenartige. Auf längere Strecken hin ähnelt diese Bewegungsweise der vieler anderer Schwimmenten: mit gleichmäfsigen, schnellen Flügelschlägen, die mit einem pfeifenden Geräusch verbunden sind, durchschneidet unsere Ente eilig die Luft, und da wegen der geringeren Gröfse der Amerikanerin die einzelnen Schwingenschläge etwas rascher auf einander folgen, als bei unsere Stockente, so macht sich dies auch akustisch entsprechend bemerkbar, auch ist das Geräusch wohl weniger intensiv als bei letzteren. Charakteristisch für das Flu g b ild ist der kurze Schnabel und lange, abgerundete, zuweilen etwas gebreitet getragene Schwanz: hieran erkennt man die fliegende Brautente schon als Silhouette gegen den Himmel, also auch ohne irgend welche Farben wahrnehmen zu können, recht gut. Wenn die Beleuchtung nicht gar zu schlecht ist, so kann man gewöhnlich die einfarbig weifse Brust recht gut unterscheiden, ein Merkmal, das nur wenigen europäischen Enten zukommt. Einen geradezu herrlichen Anblick gewährt der über die Bäume hinstreichende Erpel, wenn man ihn bei noch tiefstehender Morgensonne voll beleuchtet sieht: auch auf gröfsere Entfernungen. hin ist daun die markante Kopfzeichnung und die glänzende Oberseite deutlich erkenubar. Von oben gesehen fällt, namentlich beim Weibchen, der weifse Endrand des Spiegels, sowie, wenn die Flügel nicht zu schnell bewegt werden, das weifse Enddrittel der Handschwingen sehr auf, und ich habe daran die einfallenden Brautenten oft erkannt. Die gelben, so leuchtend weifs und schwarz gerandeten Tragfedern sind im Fluge dagegen so gut wie unsichtbar.

Eine Fähigkeit, welche vielleicht aufser der Braut- und Mandarinente keiner anderen Art zukommt, ist die, dafs die Tiere auch aus hoher Luft zwischen den Bäumen fast lotrecht auf ganz kleinen Wasserflächen einfallen können. Wenn z. B. nur eine etwa tischgrofse offene Wasserstelle sich in der Eisfläche eines Teiches befindet, der von hohen Bäumen umsäumt ist, so gewährt die Beobachtung des abendlichen Einfalles der verschiedenen Entenarten viel Interessantes. Während Stock-, Schnatter-, Spiefs-, Pfeifund andere Schwimmenten nach mehrmaligem Kreisen über den Bäumen sich häufig erst nach einigen Fehlversuchen schliefslich auf dem Eise niederlassen, um dann zu Fufs dem Wasserloch zuzuwandern, so fallen die Brautenten unmittelbar aus der Luft mitten auf die Wasserfläche, und ihre Ankunft geschieht häufig so schnell und unvorbereitet, dafs der Beobachter unsere Enten 
überhaupt erst merkt, wenn sie auf das Wasser auffallen. Gerade die kleinsten Waldteiche liebt Lampronessa ganz besonders, und man ist immer wieder erstaunt, mit welcher Geschicklichkeit und oft fast rasenden Eile die Tiere zwischen den Bäumen auf das Wasser herunter kommen. Beim Herabgleiten aus der Luft werden bei allen Zahnschnäblern die Flügelspitzen stark nach unten gehalten, und je steiler die Ente herabkommt, um so aufrechter steht die Längsachse des Vogelkörpers: aber natürlich so, dafs sich der Kopf oben, und der Schwanz unten befindet. Maler lieben es bekanntlich, einfallende Wasservögel so darzustellen, als kämen sie mit dem Kopf zuerst herunter! Es ist überhaupt eine Tatsache, auf die beim Kapitel „Vogelflug“ viel zu wenig hingewiesen wird, dafs so gut wie immer (aufser beim „Stofsen") der vordere Flügelrand höher steht, als der hintere, nur dann nämlich bleibt der sich in der Luft vorwärts bewegende Vogel oben; denn sobald der vordere Flügelrand tiefer liegt als der übrige Flügel, schlägt der Vogel nach vorn um und gerät kopfüber nach unten. Um den Fall beim Herabkommen aus der Luft etwas zu dämpfen, werfen sich unsere Enten bisweilen mit weit geöffneten Flügeln von einer Seite zur andern, ein Verhaiten, das man übrigens auch bei anderen Gattungen, z. B. bei Gänsen, leicht beobachten kann.

Die Brautente ist im Stande, sich ziemlich rechtwinklig vom Rande des Wasserspiegels zu erheben, man sieht das häufig, wenn die Vögel z. B. eine Brücke überfliegen wollen, oder wenn sie Aufbaumen. Dafs sie geschickt auch kürzere oder kürzeste Entfernungen mit Hülfe der Flügel zurücklegen können, habe ich gelegentlich ihrer Kletterkünste schon erwähnt. Natürlich vermögen unsere Vögel, auch wenn sie von einer längeren Luftreise her in voller Fahrt sind, auf Bäumen einzufallen: dies habe ich übrigens auch bei der Stockente schon beobachtet, nur stellt diese sich weit ungeschickter dabei an.

In ihrer ganzen Gewandtheit zeigt sich die Brautente, wenn es gilt, zwischen dichtem Geäst hindurchzufliegen. Man ist ganz erstaunt darüber, wie es die Tiere fertigbringen, bei ihrem raschen und doch immer recht stätigen Entenfluge nicht überall anzustofsen, und denkt jeden Augenblick, sie müfsten sich in den Zweigen verheddern, verletzen oder festhängen. Diese Fähigkeit des geschickten Ausweichens bringt es mit sich, dafs sich Lampronessa beim Umherstreichen von einem Waldteich zum andern durchaus nicht immer, wie andere Enten, erst über die Baumwipfel erhebt, sondern sie nimmt ihren Weg auch ebenso oft zwischen und unter den Ästen dahin, sodafs man die abfliegenden Brautenten sehr häufig sofort aus dem Auge verliert.

Irgend eine bestimmte Formation habe ich die Trupps im Fluge niemals einnehmen sehen, die Tiere lieben es auch nicht, in grofsen Verbänden umherzuziehen, sondern, selbst wenn sich mehrere Dutzend zugleich erheben, trennen sich in Kurzem kleinere Schwärme ab, die dann ihrerseits eine regellose Schar bilden. 
Da in unmittelbarer Nähe des Berliner Zoologischen Gartens sich vom Herbst bis in das Frühjahr hinein stets Wanderfalken ( $F$. peregrinus) aufzuhalten pflegen, die jedem Flugwild eifrig na chstellen, so passiert es nicht allzu selten, dafs diese Räuber auch a uf Lampronessa Jagd machen, es ist jedoch noch nie beobachtet worden, dafs eine solche Ente wirklich von den Falken geschlagen worden ist. Durch die fast andauerude Anwesenheit dieser Raubvögel wird der Instinkt aller unserer freifliegenden Enten, nur in vorgeschrittener Dämmerung gröfsere Flugtouren zu unternehmen, sehr gestärkt und geübt, und, wenn Brautenten durch irgend eine andere Gefahr am Tage hochgemacht werden, so fliegen sie, wenn irgend angängig, stets in Deckung, also nicht über den Bäumen, sondern zwischen diesen hindurch. Ist aber Peregrinus wirklich einmal hinter einer Lampronessa her, so weifs diese stets in rasender Eile noch zwischen dichtes Geäst zu kommen, oder aber sie fällt, wenn sie sich über Wasser befindet, rechtwinklig aus der Luft herunter, um sich dann auf der Wasserfläche vor dem Falken zu ,drücken".

\section{Verkehrsformen.}

Fast alle höheren Tiere, wenigstens soweit sie gesellig leben, besitzen eine ganze Reihe von Gefüblsäufserungen, die dazu dienen, andere Artgenossen über ibre Absichten oder Gemütsbewegungen $\mathrm{zu}$ orientieren. Ich möchte hier ausdrücklich betonen, dafs ich in keiner Weise behaupten will, dafs diese Äufserungen der Laut- und Zeichensprache vom einzelnen Individuum irgendwie in einer bestimmten Absicht hervorgebracht werden. So viel scheint aber sicher, dafs andere gleichartige oder ähnliche Tiere diese Äufserungen verstehen und häufig danach handeln.

Ich möchte dies kurz an einem Beispiel erläutern. Unter einer Brücke sucht ein Brautentenweibchen nach Futter. Etwas abseits davon befindet sich der zugehörige Erpel und bemerkt uns, wie wir auf die Brücke kommen: der Erpel kann uns also sehen, die Ente nicht. Sind die beiden Tiere nicht gar zu sehr an Menschen gewöhnt, so wird das Männchen seinen Warnungslaut, ein wiederholtes „Jiíb“ ausstofsen und rasch von uns wegschwimmen. Die Ente jedoch hat gerade den Kopf unter Wasser und merkt also nichts von dem Verhalten ihres Gatten: das hat dann zur Folge, dafs das Männchen sich nicht weiter von uns entfernt, ja sogar ein kleines Stück wieder zurückschwimmt und sich von neuem ängstlich zu gebärden anfängt. Die Ente hat inzwischen das Benehmen des Männchens wahrgenommen und kommt nun mit glatt angelegtem Gefieder und langem Hals, also mit allen Zeichen ängstlicher Vorsicht unter der Brücke hervor, um dann, uns gewahrend, ein Stück abzustreichen. Der ganze Vorgang macht auf den vermenschlichenden Beobachter den Eindruck, als habe der besorgte Erpel sein Weibchen vor einer 
Gefahr warnen wollen. Ich glaube jedoch nicht, dafs wir zu diesem Schlusse berechtigt sind. Treffen wir z. B. einen einzelnen Erpel und erschreckten ihn, so wird er ebenfalls unter denselben Warnungstönen und denselben Bewegungen die Flucht ergreifen, nur denkt er dann natürlich nicht daran, plötzlich einzuhalten, oder ein Stück umzukehren. Dieses Zögern in dem erwähnten Falle kann aber einfach darin seinen Grund haben, dafs das Männchen, welches sich namentlich vor der Brutzeit überhaupt nicht gern weit von seinem Weibchen entfernt, immer wieder zu diesem zurückzukehren bestrebt ist. Viele Beobachtungen an Vögeln und Säugetieren haben mir gezeigt, dafs Individuen, die ganz allein sind, dieselben Äufserungen der Laut- und Zeichensprache vernehmen lassen, die nach der gewöhnlichen menschlichen Auffassung doch lediglich für andere Artgenossen bestimmt sind. So warnt z. B. die Amsel (Merula merula) nicht etwa mit Absicht andere Geschöpfe durch den schirkenden "Warnruf" vor den herumstreichenden Katzen, sondern beim Anblick der letzteren stöfst jede Amsel die bekannten Rufe aus, auch wenn weit und breit kein Tier in der Nähe ist, dem diese Warnung zu gute kommen könnte Umgekehrrt ist allerdings vielen Tieren der Instinkt angeboren, solche Äufserungen der Laut- und Zeichensprache zu beachten, bezüglich richtig danach $\mathrm{zu}$ handeln: bekanntlich reagieren z. B. ganz junge Tiere sofort durch Stillsitzen u. s. w. auf die Schrecklaute ihrer Eltern, auch wenn sie in dieser Hinsicht niemals Erfahrungen sammeln konnten oder irgendwie dazu angeleitet sind. Wenn wir also im Folgenden die "Verkehrsformen" von Lampronessa und, zum besseren Verständnis auch von anderen Enten studieren wollen, so setze ich diese, ins Menschliche übersetzt, etwa auf dieselbe Stufe, wie unsere verschiedenen Gesichtsausdrücke oder die allen Menschen gleichen Interjektionen von Schmerz, Freude u. s. w., also alles Dinge, die nicht in der Absicht hervorgebracht werden, sich anderen Leuten verständlich zu machen, die aber von unserer menschlichen Umgebung recht gut erkannt werden.

Sehen wir zwei Enten - gleichviel welcher Art - sich irgendwo auf der Wasserfläche begegnen, so werden wir sehr' häufig ein Verhalten beobachten können, das ich als „Antrinken' bezeichnen möchte: das eine Stück taucht die Schnabelspitze ins Wasser und macht die Bewegung des Trinkens, der Artgenosse antwortet sofort in gleicher Weise. Ob dabei wirklich Wasser verschluckt wird, konnte ich nicht mit Sicherheit wahrnehmen. Diese Äufserung entspricht etwa dem Schweifwedeln zweier sich begegnenden Hunde, die damit bekanntlich ausdrücken, dafs sie keine feindlichen Absichten gegeneinander hegen, und man kann sicher sein, dafs auch die in Rede stehenden Enten sich wenigstens vorläufig vertragen werden. Wird dieses "Antrinken" wiederholt, so ist es ein Beweis von gröfserer Zuneigung: besonders die Gatten eines Paares üben diesen "Comment" stets, wenn sie sich auch 
nach kurzer Trennung wieder treffen. Bei Lampronessa wird diese Trinkbewegung unmittelbar vor der Paarung vom Erpel in rascher Folge mehrfach ausgeführt und ist hier also ein Ausdruck der Zärtlichkeit.

Falls keine freundschaftlichen Absichten zwischen zwei sich nahe kommenden Brautenten herrschen, so sehen wir, wie die eine mit vorgestrecktem Halse und offenem Schnabel auf die andere losschwimmt, ohne jedoch wirklich $\mathrm{zu}$ beifsen, worauf die andere meist Reifsaus nimmt. Dieses „Drohen" dient also dazu, die andere Ente zu verjagen, und hat auch gewöhnlich den gewünschten Erfolg, obgleich beim eigentlichen Kampfe der Schnabel gar nicht als Waffe verwendet wird. Geraten nämlich zwei männliche Stücke, besonders in Liebeshändeln, wirklich ernstlich aneinander so sehen wir sie, nach erregtem Hin- und Herschwimmen plötzlich etwa $20 \mathrm{~cm}$ von einander entfernt, immer gleichen Abstand haltend, in eiligster Weise neben einander auf dem Wasser hinschiefsen. Plötzlich werden, und zwar ganz unvermutet, rasche Flügelschläge nach dem Gegner geführt, die natürlich in entsprechender Weise erwidert werden, die Kämpfer sind dann oft in einen dichten Sprühregen eingehüllt. Schliefslich ergreift einer die Flucht, entweder indem er untertaucht oder indem er ein Stückchen abseits fliegt. Niemals habe ich gesehen, dafs die Tiere den Schnabel zum Kämpfen benutzen, wie es ja sonst bei den meisten anderen Entenarten die Regel ist. Bei dieser Kampfesweise wird es erklärlich, dafs Lampronessa eine ungemein zarte Haut besitzt: man ist beim Abziehen einer Brautente ganz erstaunt über die Feinheit und leichte Zerreifsbarkeit des Balges. Man wird stets die Beobachtung machen, dafs Vögel, welche sich gegenseitig mit einem harten Schnabel oder scharfen Krallen zu Leibe gehen, auch eine entsprechend derbe Haut als Schutzmittel gegen diese Waffen besitzen. Alle von mir beobachteten Zahnschnäbler deuten durch besondere Zeichen an, wenn sie aufzufliegen beabsichtigen. Meist besteht dies darin, dafs sich der Vogel sehr schlank macht und Kopf und Schnabel auf dem hocherhobenen Hals in ganz eigentümlich ruckweise Bewegungen versetzt. Die Stockente z. B. schnellt auf sehr charakteristische Art mit dem Schnabel von unten nach oben; die meisten Gänsearten schütteln seitlich mit dem Kopf u. s. w. Beabsichtigt eine Brautente aufzufliegen, so wird Hals und Kopf ähnlich aber weniger ruckweise bewegt, wie dies im entsprechenden Falle bei vielen Tauben zu sehen ist: der Vogel streckt den Kopf langsam von hinten nach vorn, und es kommt eine typische Zielbewegung zustande. Dabei wird das ganze Gefieder ganz glatt angelegt und sowohl die Ente wie der Erpel pflegen einen ganz bestimmten Ton auszustofsen. Aufserdem strecken unsere Vögel häufig die Flügel, sei es, dafs sie die zusammengelegten Schwingen nach oben über den Rücken nehmen, sei es, dafs der Flügel einer Seite zugleich mit dem betreffenden Bein weit vom Körper abgespreitzt wird; der anthropocentrisch 
denkende Mensch könnte meinen, dafs sie vor dem Fluge geradezu mit Absicht ihre Flügel erst in Ordnung brächten!

Stimme. Bekanntlich liegt bei fast allen Entenmännchen an der Zweiteilungsstelle der Luftröhre eine sogenannte Knochentrommel, ein blasiges, mehr oder weniger unsymmetrisches Gebilde, das nicht etwa dazu dient, die Stimme zu „Verstärken", wie man dies oft angegeben findet, sondern ihr einen vollständig von der des Weibchens verschiedenen Charakter verleiht, und wir müssen daher die Stimmen der beiden Geschlechter durchaus gesondert betrachten.

Die Stimme der Brautenten-Weibchen hat in fast allen ihren Abstufungen etwas eigenartig Klägliches und erinnert in mancher Hinsicht an die Lautgebung bestimmter Froscharten. Der eigentliche Lockton, den man auf grofse Entfernungen hin und häufig im Fluge hört, namentlich beim Aufstehen, oder wenn die Tiere ihre Richtung über ein Gewässer nehmen, auf dem sie ihre Genossen vermuten, ist ein in Buchstaben nicht gut wiederzugebendes, auch sehr schwer, am besten noch mit Fistelstimme nachzuahmendes „Huäk", ein Ton, der von dem Uneingeweihten, namentlich wenn er ihn bei vorgeschrittener Dämmerung aus der Luft hört, nicht leicht einer Ente zugeschrieben wird. Sehr ähnlich ist die Stimmäufserung, welche man als Warnu ngston bezeichnen könnte, d. h. also, die beim Herannahen einer Gefahr ausgestofsen wird, sie klingt jedoch etwas spitzer, mehr wie „Huíck“, ist kürzer und wird schärfer betont. Eine Modifikation des eigentlichen Locktones, wie sie kurz vor dem Auffliegen hervorgebracht und dann mit den oben beschriebenen Intentionsbewegungen verbunden wird, ist ein langes und fein ausklingendes „Huí": man glaubt es dieser Stimmäufserung geradezu anzuhören, dafs das Tier im nächsten Augenblick abstreichen wird. Ein anderer Ton, den das Weibchen namentlich vom Herbst his zur Brutzeit hin im Schwimmen oder am Ufer stehend hören läfst, kann etwa mit „Kruí“ oder ,Kerrí“ (in Fistelstimme) übersetzt werden, er scheint mir eine gewisse kokette Gemütsstimmung auszudrücken und speziell den Erpeln zu gelten.

Ganz andere Töne bringt die weibliche Brautente hervor, wenn sie auf die Nestsuche geht. Man hört dann, oft viertelstundenlang und länger, ein ziemlich leises, gleichsam erzählendes, fortlaufendes „Tětětětět" (in Fistelstimme gesprochen), und dieser Ton wird besonders dann hervorgebracht, wenn die Ente auf den Ästen herumsitzt und mit vorgestrecktem Halse nach Baumhöhlen sucht: man kann an diesem Gemurmel den Eintritt der eigentlichen Fortpflanzungsperiode erkennen. Wohl derselbe Ton ist es, den die Ente auch ausstöfst, wenn sie ihre Jungen aus der Nesthöhle führen will: er ist anscheinend mit all den Verrichtungen verbunden, die zur letzteren in Beziehung stehen. Etwas abgeändert und viel kürzer wird dieses ,Tĕtĕtĕtět" auch häufig hervorgebracht, 
wenn im Herbst und Winter Enten und Erpel namentlich mit Beginn der Dunkelheit die später noch zu beschreibenden „Verlobungsspiele“ ausführen: man könnte diese Stimmäufserung so auffassen, als rege die Ente die anwesenden Männchen durch den "Nestton" besonders an.

Ein ganz leises, nur in nächster Nähe hörbares,,Tĕtĕtět" u.s. w. hört man von der weiblichen Ente, wenn man sie z. B. eng einsperrt, und sie nun einen Ausweg suchend am Gitter hin und herläuft: es drückt Ungeduld und die energische Absicht, sich zu entfernen, aus.

Alle Tonäusserungen des Erpels bewegen sich mehr oder weniger in einem hohen zirpenden „Ji“, und der Lockt on kann etwa mit „Jī̄b“, bei welchem das letzte „i“ stark betont und in die Länge gezogen wird, wiedergegeben werden. Man hört es sowohl im Sitzen als auch im Fliegen und Schwimmen, und diese Stimmäufserung klingt zwar unbedeutend, wirkt aber doch recht ansprechend. Bei dem W arnungston wird dieses „Jiīb" insofern abgeändert, als das hier ebenfalls betonte letzte i kurz ausgestofsen wird, also etwa „Jiı̈b". Ein Ton, welcher das bevorstehende Abstreichen ausdrückt, läfst sich etwa durch ein sanftes „Jir", am Schlusse sehr in die Länge gezogen und recht leise ausklingend, wiedergeben. Begleitet der Erpel sein Weibchen auf der Nestsuche, so läfst er fortgesetzt ein leises „Jübjübjibjüb“ vernehmen, das also dem „Tětětětět" der Ente entspricht. Auch wenn der Brauterpel mit seiner Ente umherschwimmt und in der bei unserem Vogel üblichen Art den eleganten Kavalier spielt, pflegt er ein leises, oft zwar einzeln ausgestofsenes, aber wiederholtes ,Jiíb" vernehmen zu lassen, und bei den abendlichen Zusammenkünften, wo es gilt, die gegenseitige Bekanntschaft $\mathrm{zu}$ machen, und - im menschlichen Sinne gesprochen - den anderen Genossen zu zeigen, ,wer man ist", wird dieser zirpende, zwitschernde Laut in vielen Modifikationen zum Ausdruck der Freundschaft und Feindschaft verwendet.

Bei lauteren Stimmäufserungen sträubt der Erpel bei jedem einzelnen Ton die Haube, vor allem, wenn er beim Umzwitschern seiner Ente mit hoch aufgerichtetem Halse sein „Jī̄b“ zum Besten gibt.

Hört man, namentlich im Dunkel der späteren Abendstunden, einen oder mehrere Erpel am dichtbewachsenen Ufer lautgeben, ohne sie sehen zu können, so ist man leicht geneigt, ihr Zirpen und Gewisper einer Rattengesellschaft zuzuschreiben: damit ist die Stimmlage des Brauterpels gut gekennzeichnet. Alle Lautäufserungen der männlichen Brautente sind viel leiser, als die entsprechenden des Weibchens, wie dies ja bei sämtlichen Zahnschnäblern der Fall ist, bei denen ein stimmlicher Dimorphismus besteht.

Die kleinen Dunenjungen piepen in ähnlicher Weise wie andere Entchen, ihre Stimme weicht jedoch z. B, von der 
junger Stockenten insofern ab, als sie nicht wie letztere einzelne, gezogene Pfeiftöne ausstofsen, sondern gewöhnlich zwei unmittelbar aufeinander folgen lassen, auch ist ihre Stimme nicht so laut, wie die der jungen $A$. boscas. Dieser Jugendton ist bei beiden Geschlechtern zunächst völlig gleich, und erst, wenn unsere Vögel anfangen, sich ordentlich $\mathrm{zu}$ befiedern, machen sich Stimmunterschiede bemerkbar. Ja selbst, wenn die jungen Enten bereits zu fliegen anfangen, kann man bei ihren Lauten noch über das Geschlecht im Zweifel sein. Das für die Weibchen sonst so charakteristische "Huäk" klingt dann noch so fein und spitz, dafs es sehr an das ,Jiïb" des alten Erpels erinnert.

Kurz möchte ich noch bemerken, dafs die Stimmäufserungen der nahe verwandten Mandarinente recht ähnlich sind, aber dabei doch sehr charakteristische Unterschiede aufweisen. An Stelle des „Jiīb“ des Brauterpels tritt hier ein merkwürdiges „Uỉb“, aus dem man bisweilen einen eigenartigen Grunzlaut heraushört, und dessen zweite Silbe kurz hervorgestofsen wird. Beim Mandarinenten-Weibchen liegt die Stimme höher, als bei der Brautente, und die Töne werden kürzer und abgerissener hervorgebracht.

\section{Fortpflanzung.}

Über das Li e besleben auch unserer einheimischen Enten sind derartig unklare Ansichten verbreitet, dafs ich zum besseren Verständnis der Balzformen der Brautente etwas weiter ausholen möchte. Ziehen wir zum Vergleich unsere wegen ihrer grofsen Häufigkeit und ihrer in manchen Parkanlagen geradezu überraschenden Zahmheit am leichtesten $\mathrm{zu}$ beobachtende Stockente heran, so gilt für letztere etwa folgendes. Schon im ersten Beginn des Herbstes, wenn die alten Erpel ihr Prachtkleid ziemlich vollständig angelegt haben, und späterhin bis etwa zum Ende des Februar finden wir öfters, namentlich an schönen Tagen, auf dem Wasserspiegel etwa ein Dutzend Enten beiderlei Geschlechts versammelt, die ein eigentümliches „Gesellschaftsspiel" ausführen. Wir sehen plötzlich ein Entenweibchen mit weit vorgestrecktem Halse in merkwürdig eiliger Weise zwischen den Versammelten dahinschwimmen, und auf dieses Zeichen hin lassen eine Anzahl Erpel den für die männlichen A. boscas so charakteristischen hohen Pfeifton hören. Sie richten sich dabei mit einem Ruck im Wasser auf, und die Schnabelspitze berührt für einen Augenblick etwa die Mitte der Brust. Die anderen Erpel, die dieses Pfeifen anscheinend versäumt hatten - denn es geschieht gewöhnlich von den diesen Ton hervorbringenden Individuen ganz gleichzeitig - richten den Schwanz etwas auf, so dafs die sogenannten Erpelfedern zur vollsten Geltung kommen, legen den eingezogenen Kopf und Hals weit nach dem Rücken zurück und lassen dabei ein, ihrem sonstigen 
Lockton ähnliches, tiefes, nicht eben lautes „Räb“ hören. Nach dieser Produktion pHlegen sich die Erpel wieder in Positur zu setzen, das heifst, sie schütteln sich und rücken sich in eigentümlicher Weise zusammen. Es dauert nicht lange, und dasselbe Spiel beginnt vom neuem und wiederholt sich oft viertelstundenlang. Sämtliche Beteiligte sind dabei ganz dicht versammelt, es herrscht allgemein Friede und Eintracht, und man hat die Empfindung, als wenn die Erpel mit ihren schönen Farben und ihrem pfeifenden Balzlaut prahlen wollten. Namentlich solche weibliche Enten, welche noch keinen bestimmten Erpel haben, reizen durch das oben beschriebene merkwürdige Umherschwimmen die Männchen gern zum Balzspiel: man kann dies sehr leicht beobachten, wenn man die einzelnen Individuen persönlich kennt, man weifs dann genau von ihnen, dafs sie noch ,unverheiratet" sind, und, wo solche Enten ein paar Erpel versammelt sehen, beginnen sie gewöhnlich sofort mit dieser Koketteriebewegung. Die Körperhaltung, in welcher die Weibchen dieses „Gesellschaftspiel“ anregen, ist gewissermafsen eine Nachahmung der Lage, die das Weibchen bei der Aufforderung zum Treten annimmt: man könnte sie also wohl als Intentionsbewegung oder -stellung bezeichnen. Ausdrücklich sei bemerkt, dafs bei diesem Gesellschaftsspiel die Tiere niemals zur Begattung schreiten, es dient nur dazu, die nähere Bekanntschaft zu machen, man setzt sich den anderen gegenüber „ins rechte Licht", etwa so, wie wir es gelegentlich eines Balles u. s. w. tun. Gegen das Frühjahr hin haben sich auch die jüngeren Stücke gegenseitig gefunden, und mit dem Eintritt der eigentlichen Fortpflanzungsperiode hört diese Balz vollkommen auf.

Schon Ende September kann man wirkliche Begattungen bei der Stockente sehr häufig beobachten. Die Vögel ,treten sich": täglich und unterlassen dies nur in der kältesten Winterzeit, bei Futtermangel u. s. w.: mit dem Beginn der Eiablage hat dieses Treten nichts zu tun, worauf übrigens schon der alte Gessner sehr richtig hinweist. Dabei ist, namentlich im Beginn des Herbstes, gewöhnlich die Ente der auffordernde Teil, und die Erpel haben um diese Zeit, in der das Prachtkleid oft noch nicht einmal ganz ausgebildet ist, dafür häufig wenig Verständnis. Bekanntlich fordern sich Stockerpel und -enten in der Weise zum Treten auf, dafs sie in ruckweiser Art den Kopf fortgesetzt von oben nach unten bewegen, wobei die Längsachse des Schnabels dauernd parallel dem Wasserspiegel bleibt. Diese Bewegung wird immer heftiger, bis sich das Weibchen mit weit vorgestrecktem Kopf flach aufs Wasser legt und nach der Seite hin, auf welcher sich ihr Männchen befindet, sich merkwürdig abflacht, sodafs ihre Oberseite geradezu eine schiefe Ebene, sehr bequem zum Ersteigen, bildet. Die Paarung selbst geht alsdann von statten und das Männchen führt ein eigentümliches „,Nachspiel“ aus, indem es, unmittelbar nachdem es den Rücken des Weibchens verlassen 
hat, in ganz merkwürdiger, aber sehr charakteristischer Weise, gewöhnlich in einem Halbkreis um das Weibchen herum auf dem Wasserspiegel hinschiefst. Da den Tieren, namentlich dem Weibchen, bei dem ganzen Vorgang Wasser an die Flügel und unter die Tragfedern gekommen ist, so wird unmittelbar darauf eifrig Toilette gemacht.

Auch bei der Stockente halten die Paare mit Ausnahme der Brut- und Mauserzeit stets gut zusammen. Es scheint, dafs die Ehe zwischen denselben Individuen jeden Herbst immer wieder erneuert wird, den während die Ente Junge, führt und die Erpe! mausern, sind die Gatten natürlich weit auseinander gekommen. Da aber beide im Herbst dieselben Örtlichkeiten wieder aufsuchen, so treffen sie sich dort wieder und halten dann sofort zusammen: dies ist für die Tiere auch einfacher, als wenn sie jedes Jahr wieder auf neue Erwerbungen ausgehen müfsten.

Gegen Ende des Winters, wenn sich die ersten warmen Tage einstellen, ändert sich dieses friedliche Bild ganz und gar. Ein Beispiel wird dies am besten erläutern. Nehmen wir an, an einem Ende des Teiches befindet sich das Stockentenpaar A, die Ente friedlich nach Nahrung suchend, denn sie mufs Reservestoffe für die Eierproduktion sammeln, der Erpel in gewohnter Weise mit hoch erhobenem Kopfe sichernd. Da fällt 100 Meter davon ein zweites Paar B ein, Erpel A rudert eiligst auf die fremde Ente los, um unmittelbar darauf direkt zu ihr zu fliegen, sie aber steht im letzten Moment auf, und eine tolle Luftjagd beginnt. Höher und höber schraubt sich die verfolgte Ente, dahinter der fremde Erpel, und das Männchen des Paares B, ihr rechtmäfsiger Ehemann, mufs wohl oder übel folgen, da er ja nicht wissen kann, wo seine Ente schliefslich bleiben wird. Man sieht also 2 Erpel einer Ente nachfliegen, und das wird gewöhnlich so gedeutet, als wenn die Erpel eine Ente treiben. In Wirklichkeit aber treibt e in fremder Erpel die Ente eines zusammengehörigen Paares. Schliefslich bekommt der Erpel A die Sache satt und kehrt auf geradem Wege zu seiner Ente zurück.

Jeder Erpel scheint das ganze Frühjahr hindurch an nichts weiter zu denken, als wie er fremde Weibchen notzüchtigen kann. Es kommt dabei zu geradezu wüsten Scenen, und den Enten wird in schrecklicher Weise zugesetzt, sie wagen sich schliefslich garnicht mehr ins Wasser und kriechen mit ihrem Gatten verstohlen unter dem Gebüsch umher. Hat man, wie im Zoologischen Garten, einige amputierte Stockentenweibchen, so werden diese, da sie ja den fremden Männchen nicht entfliehen können, einmal nach dem anderen vergewaltigt und bisweilen direkt zu Tode gehetzt.

Die Ente ihrerseits ist ihrem Männchen in geradezu rührender Weise treu. Ich habe oft beobachtet, wie sie sich, nachdem sie mehreren fremden Erpeln glücklich entronnen ist, ihrem Gatten zum Treten anbietet, und dann kann es vorkommen, dafs der Letztere, der nur immer nach fremden Weibchen Ausschau hält, 
von ihr nicht einmal etwas wissen will! Die weibliche St ockente ist demnach streng monogam, die männliche im Frühjahr in reingeschlechtlicher Beziehung ${ }^{1}$ ) polyg a m, ein Verhalten, auf das bisher nie in gebührender Weise aufmerksam gemacht worden ist. Der eigenen Ente gegenüber ist der Erpel stets sehr rücksichtsvoll. Es kommt überhaupt nie vor, dafs ein Entenmännchen sein Weibchen „treibt", wie man gewöhnlich zu sagen pflegt, sondern alle Paarungen werden stets im gegenseitigen Einverständnis, meist nach Aufforderung durch die Ente, ausgeführt, auch die Brautwerbung geschieht nie in der Weise, dafs der männliche Vogel ,hinter dem Weibchen her ist", sondern die Geschlechter lernen sich, wie schon beschrieben, bei ihren "Gesellschaftsspielen“" kennen, und die Paare bilden sich auf ganz ungezwungene Art.

So treiben es die meisten Schwimm- und Tauchenten, bei einigen Arten ist die Polygamie der Männchen mehr, bei anderen weniger ausgebildet. Nach diesen einleitenden Betrachtungen wollen wir uns wieder der Brautente zuwenden. Hier treffen wir auf wesentlich andere Verhältnisse. Dem Erpel fehlt, wie bereits erwähnt, ein eigentlicher Balzton, ebenso vermissen wir auch die bei der Stockente näherbeschriebenen herbstlichen und winterlichen Gesellschaftsspiele fast ganz, denn sie sind so wenig ausgeprägt, dafs sie kaum mehr diesen Namen verdienen. An ihre Stelle ist beim Erpel ein Verhalten getreten, welches ich als vollendetstes „Kavaliertum“ bezeichnen möchte. Treffen sich, namentlich abends, auf besonders beliebten Gewässern eine Anzahl Erpel und Enten, so tragen die Weibchen dadurch, dafs sie ebenfalls eine bestimmte Koketteriestellung einnehmen und einen gewissen Ton ausstofsen, zur Erregung der Männchen bei. Letztere schwimmen dann so dicht wie möglich herbei, richten die Haube auf, zirpen und wispern in verschiedenen Tonabstufungen und suchen sich gegenseitig aus der Nähe der Umworbenen zu verdrängen, wobei es auch bisweilen zu Kämpfen kommt. Sie schiefsen oft in merkwürdiger Weise auf die Ente los, sodafs es den Anschein hat, als wollten sie wütend auf diese losbeifsen. Dann legt letztere bisweilen, genau wie bei der Paarungsstellung, den Hals lang aufs Wasser, das Männchen hält mit einem plötzlichem Ruck an und kuabbert ihr sanft im Kopf- und Halsgefieder: eine gegenseitige Liebeserklärung, wie sie deutlicher für die Brautenten-Zeichensprache gar nicht ausgedacht werden kann!

Auch das bei vielen Zahnschnäblern beliebte „Hetzen“, d. h. das Beifsen und Schimpfen des Weibchens nach" fremden sich nähernden Artgenossen, wie dies bei den Kasarka-Arten am aus-

1) Diesen einschrănkenden Zusats halte ich für nötig. Ein vollkommen polygames Mănnchen würde das Bestreben haben, sich ein€n „Harem“ anzulegen, d. h. also mit vielen Weibchen in gleichmăfsiger Weise zu leben. Der Stockerpel dagegen lebt nur mit einem Weibchen und will die andern nur "treten", nicht aber auch sonst zu ihnen balten.

(H.) 
geprägtesten vorkommt, kann man bei Lampronessa ab und $\mathrm{zu}$ beobachten: sie spornen dadurch ihren Gatten zum Kampfe an und „schmeicheln sich durch Schimpfen auf andere bei ihm ein". Beobachten wir ein einzelnes Paar abseits vom geselligen Treiben, so werden wir finden, dafs der Erpel seine Gattin in wirklich zierlicher Weise umschwimmt, ihr überall den Vortritt läfst, und, wenn sie gerade ganz dicht an ihm vorbeikommt, den Kopf hoch aufrichtet, die Haube sträubt und seinen etwas modifizierten Lockton hören läfst. Findet das Männchen einen gröfseren Nahrungsbrocken, so nimmt es ihn auf und hält den Bissen in der Schnabelspitze in geradezu reizender Weise mit hoch erhobenem Kopfe dem Weibchen hin, das ihn dann abnimmt und verzehrt. Dieses Füttern konnte ich bisher bei keiner anderen Entenart beobachten.

Die Paarungsaufforderung der Brautente ist wesentlich anders, als die bei Anas boscas. Das Weibchen legt sich lang aufs Wasser, und es sieht für den Uneingeweihten aus, als sei es verendet: ganz unbeweglich verharrt es für viele Minuten in dieser Lage. Wir sehen dann das Männchen dicht neben ihr die für die Begrüfsung charakteristische T'rinkbewegung ausführen: fortwährend taucht er die Schnabelspitze ins Wasser, um dann den Kopf rasch wieder hoch zu erheben. Gewöhnlich nimmt er sich recht viel Zeit, und braucht lange zu diesen Vorbereitungen, entfernt sich auch wohl ab und zu, und seine Gattin schwimmt ihm dann, immer in der beschriebenen Haltung, nach. Schliefslich wird die Paarung ausgeführt, vom Weibchen hört man im Augenblick des „Hängens" oft den leisen Lockton, und das Männchen springt mit einem eigentümlichen Satz von ihrem Rücken, führt aber dann kein so charakteristisches Nachspiel aus wie der Stockerpel, sondern schwimmt hoch erhobenen Hauptes seitlich etwas davon.

Solange keine überzähligen Erpel vorhanden sind, herrscht dauernd Ruhe und Frieden, ich habe wenigstens kaum beobachtet, dafs sich ,verheiratete" Brautentenmännchen um fremde Weibchen kümmern, wenigstens solange ihr eigenes noch nicht brütet. In diesem Jahre hatten wir nun eine grofse Überzahl von Männchen, und da kam es denn, allerdings erst bedeutend später als bei den Stockenten, doch schliefslich zu ähnlichen Scenen, wie bei der letzterwähnten Art. Die weibliche Brautente rettet sich dabei vor den fremden Bewerbern weniger durch Wegfliegen, als durch Tauchen und dadurch, dafs sie sich aufs Land begibt. Auch bei ziemlich hitziger Verfolgung sind übrigens die fremden Brauterpel nie so rücksichtslos, wie die männlichen Anas boscas.

Die Mandarinente ähnelt in ihrem Liebesleben mehr der Stockente als ihrer amerikanischen Verwandten. Hier gibt es eigentliche und zwar sehr ausgebildete "Gesellschaftsspiele", bei denen besonders die Fächerfedern und die prächtig entwickelte Kopf- und Halsbefiederung gezeigt werden, auch haben die 
Mandarinerpel im Frühjahr sehr ausgesprochene polygame Neigungen, natürlich ebenfalls nur soweit das eigentliche ,Treten" in Frage kommt. Es sei schliefslich noch bemerkt, dafs die Balz z. B. der Stock- und Mandarinerpel, die ich hier meist als "Gesellschaftsspiel“" bezeichnet habe, so gut wie nie ausgeführt wird, wenn sich nur ein Männchen bei der Ente befindet. Sie dient gewissermafsen zum Wettbewerb mit gleichgesinnten Rivalen, auch hat sie, wie ich schon bei der Stockente erwähnte, bei allen Anatiden nie etwas mit der eigentlichen Begattung zu tun.

Bekanntlich sieht man, wenigstens in den Prachtkleidmonaten, immer die Ente dem Erpel vorausfliegen, und dies hat wohl auch schon häufig zu der Annahme geführt, dafs der letztere „treibe“, eine Ansicht, die geradeso unsinnig ist, als wenn man von einem Herrn, der einer Dame den Vortritt läfst, etwas Derartiges behaupten wollte. In Wirklichkeit fliegt eben das Männchen seinem Weibchen überallhin nach, sie allein bestimmt die Richtung. Im Herbst ist dies noch nicht so ausgeprägt wie späterhin, sodafs es dann auch vorkommen kann, dafs der Erpel die Führung übernimmt.

Da wir in diesem Frühjahr, wie bereits erwähnt, viel mehr männliche als weibliche Brautenten hatten, so taten sich auch mehrere unbeweibte Erpel je zu zweit zusammen und hielten sich dann unzertrennlich wie ein richtiges Paar. Wollten sie sich treten, so begannen zunächst beide mit der bei den Männchen üblichen Vorbereitung (Antrinken u. s. w.), schliefslich übernahm aber einer die Rolle des Weibchens und legte sich wie ein solches flach aufs Wasser, um dann sofort von dem Genossen bestiegen zu werden. Der Begattungsakt wurde dann genau in der Weise ausgeführt wie bei einem richtigen Paare.

Hat man dagegen z. B. in einer Volière, mehr Weibchen als Männchen, oder sind letztere nicht tretlustig, so kommt es auch bisweilen zu sehr intimen Verhältnissen zwischen den weiblichen Enten. Nachdem die eine zur Paarung aufgefordert hat, wird sie von der andern bestiegen, und die letztere entwickelt beim Tretakt vollkommen die Geschicklichkeit eines Erpels: ja was das Merkwürdigste ist, sie führt auch dasselbe Nachspiel aus, das man nach der Begattung vom Männchen zu sehen gewohnt ist. Natürlich fehlt aus aratomischen Gründen bei diesen Weibchen-Paarungen das eigentliche „Hängen“. Genau dasselbe Verhalten habe ich übrigens auch bei Haus- und Türkenenten (Cairina) beobachtet, und die sehr häufigen TäubinnenPaare sind ja oft erst daran als solche zu erkennen, dafs sich schliefslich 4 statt 2 Eier im Neste finden.

Besonders auffallend an solchen gleichgeschlechtlichen Paaren ist mit der Umstand, dafs ein Männchen ein vollkommen weibliches Verhalten annehmen kann und umgekehrt, denn man ist von vornherein geneigt anzunehmen, dafs nur die seinem Geschlechte normalerweise zukommenden Lebensäufserungen in der Physiologie und Psyche eines Individuums enthalten sind. In allen diesen 
Fällen handelt es sich, wie ich ausdrücklich betonen will, natürlich nicht um eigentlich homosexuelle Tiere: die Brauterpel eines „Männchen-Paares“ z. B. lieben sich nur deshalb, weil sie keine Weibchen bekommen konnten und geben ihr Verhältnis sofort auf, wenn die nötigen Enten vorhanden sind.

Nestsuche. Wenn zu Ende des Winters sich die ersten warmen Tage einstellen, so sitzen in den Morgenstunden in der Nähe der Teiche Brautenten beiderlei Geschlechtes auf dicken Ästen, zum Teil in sehr beträchtlicher Höhe umher, und bevor wir sie durch das Auge wahrnehmen, werden wir durch das fortwährende, leise, schnatternde „Tětětětět" der Enten und das wispernde ,jübjübjĭb" der Erpel auf die Vögel aufmerksam: der Kenner weifs, wenn er diese Töne hört, sofort, dafs jetzt die Nestsuche im Gange ist. Gewöhnlich beginnt die Sache so, dafs nach längerem, zielendem Umheräugen ein weibliches Stück vom Wasser aus aufbaumt, der zugehörige Erpel folgt nach, und dann geht es unter Umherspähen weiter von Baum zu Baum, und auch Dächer und Schornsteine werden gern als Sitzplätze aufgesucht. Zunächst ist die Nestsuche noch nicht sehr ernst gemeint: nach kurzem Umherstreifen fallen die Enten wieder auf das Wasser ein, und es gehört schon Glück dazu, um überhaupt Gelegenheit zu haben, diese kurze Umschau zu beobachten. Mit der vorrückenden Jahreszeit wird die Suche aber ernster. Sie beschränkt sich dann nicht nur auf den frühen Morgen, sondern wird bisweilen auf die ersten Vormittagsstunden ausgedehnt; ja, es kann vorkommen, dafs man die Tiere auch gegen Abend noch sich auf den Bäumen umhertreiben sieht, bezüglich hört. ${ }^{1}$ ) Findet das Paar eine Höhle, so hängt sich gewöhnlich zunächst das Weibchen, dann auch oft das Männchen (s. Tafel I, Bild 3), nach Spechtart vor dem Eingang auf, indem sie sich, mit den Füfsen an der Rinde angeklammert, auf den Schwanz stützen, welcher aber von unseren Enten dabei, im Gegensatz zu den Spechten, ausgebreitet wird. Nun wird eifrig, jedoch zunächst sehr vorsichtig, in das Innere der Höhle hineingeschaut, schliefslich wagt sich der Vogel aber in den Eingang selbst. Da er nun durch seinen Körper das Innere der Höhle verdunkelt, so zaudert er gewöhn-

1) Diese Nestsuche der Brautente ist geradezu ein klassisches Beispiel einer reinen Instinkthandlung, denn sie wird auch von Stücken, die unter einer Henne grols geworden sind und nie in ihrem Leben eine Höhlung gesehen haben, in zweckmäfsiger Weise ausgeführt: eine hochkomplicierte Handlung geht also vollkommen der Erfahrung des Individuums voraus, die Ente sucht geradezu nach einem Dinge, von dessen Existenz sie gar keine Ahnung haben kann. Auch kann die jüngere Ente unmöglich wissen, dafs sie Eier legen und brüten wird, es mufs ibr also nicht nur jede Vorstellung von dem Gegenstande, nach dem sie sucht, sondern auch davon, wozu sie ihn verwenden will, fehlen. Natürlich handeln auch andere Vögel in ăhnlicher Weise. 
lich noch mit dem Hineinkriechen, endlich schlüpft er aber doch in das Loch und fängt dann an, das Innere näher zu untersuchen, indem er sich dabei im Kreise dreht und Wände und Unterlage mustert. Es kann dabei vorkommen, dafs sich beide Gatten für kurze Zeit zugleich in dem Baumloch aufhalten und für den Beobachter auf kurze Zeit verschwinden. Nach einer Weile streichen die beiden wieder ab, fast regelmälsig unter lautem Rufen dem nächsten Gewässer zueilend. Nicht immer verläuft die Sache so ohne Störung. Namentlich eine in der Nähe eines beliebten Gewässers gelegene Höhle wird meist von vielen Enten bald entdeckt, und häufig kriechen mehrere Paare unmittelbar hintereinander in die Tiefe, ja, zwei Weibchen treffen sich gar nicht selten in der Höhle, wobei es jedoch niemals zu Kämpfen kommt: die Tiere machen nur einige Schnabelbewegungen gegeneinander, aber dabei bleibt es auch. Nur wenn auf den Ästen sich die verschiedenen Paare zu nahe kommen, verjagen sich die Erpel auf die Weise, dafs sie dem Nebenbuhler etwa auf Spannenlänge nahe rücken und ihn aus dem Wege zu befördern suchen; sehr ernst ist aber auch dann die Sache nicht gemeint. Diese Verträglichkeit bringt es leider mit sich, dafs garnicht selten mehrere Weibchen zugleich in besonders beliebte Höhlen legen. Natürlich kann dann ein ungestörtes Brüten nicht stattfinden, oder die Jungen kommen zum mindesten ungleich aus, da während das erstè Weibchen schon brütete, das andere noch zulegte, und der Erfolg der ganzen Brut ist damit in Frage gestellt. Irgend eine Bevorzugung einer gewissen Höhe über dem Erdboden oder einer bestimmten Lage nach den Himmelsrichtungen oder im Verhältnis zum Wasser habe ich bei der Nestwahl nie feststellen können.

Da es im Berliner Zoologischen Garten an natürlichen Baumhöhlen fehlt, so mufste ich daran denken, unseren Brautenten Ersatz für diese zu schaffen, und wir haben denn eine grölsere Anzahl von Nistkästen auf den Bäumen aufgehängt, die von den Enten ohne weiteres angenommen wurden. Hohle Baumstämme wurden der Quere nach in etwa $1 / 2 \mathrm{~m}$ lange Stücke zerlegt, die Höhlung oben und unten mit einem Brett verschlossen, und in das Stammstück ein Loch gebohrt. Des besseren Aussehens und der Haltbarkeit wegen streichen wir die Holzschnittflächen mit brauner oder dunkelgrüner Ölfarbe an, so dafs das Ganze den Eindruck eines v. Berlepsch'schen Naturnistkastens macht. Die GröIse dieser Kästen richtet sich nach dem vorhandenen hohlen Stammmaterial, ist also ziemlich verschieden. Ich habe gefunden, dafs ein Durchmesser der Höhle von mindestens $21 \mathrm{~cm}$ und ein Durchmesser des Flugloches von etwa $11 \mathrm{~cm}$ bei einer Höhlentiefe von etwa $30-40 \mathrm{~cm}$ den Anforderungen der Brautente am besten gerecht wird. Um Störungen der Ente durch Artgenossen oder andere Vögel möglichst $\mathrm{zu}$ vermeiden, sehe man von der Anbringung eines 
Astes oder dergl. vor dem Flugloch ab! Oft sind diese Nistkästen natürlich auch bedeutend gröfser und haben insbesondere eine viel beträchtlichere innere Weite. Findet sich an dem Stamm ein natürlicher Eingang in Gestalt eines ausgefaulten Astes, so ist das Flugloch häufig nicht nur unregelmäfsig gestaltet, sondern es hat oft auch einen viel gröfseren Durchmesser als vorhin erwähnt. Alles dies stört aber die Brautente nicht, nur zu kleine Kästen werden nicht gern angenommen. Auch auf das Gesamtaussehen legt Lampronessa keinen Wert: denn selbst in einem für diesen Zweck aufgehängten Fäfschen, in dessen Wand ich zwischen den eisernen Fafsreifen ein viereckiges Loch schneiden liefs, fand ich in kurzer Zeit ein Gelege.

Die Höhle fülle ich etwa $10-15 \mathrm{~cm} \mathrm{hoch} \mathrm{mit} \mathrm{altem}$ Laub, Heideerde, fein zerstückeltem Torfmull u. dergl., in diese Unterlage gräbt sich die Ente ein Loch, legt in die entstandene Mulde ihre Eier und umgibt dann das Gelege mit dem für die Zahnschnäbler charakteristischen Daunenkranz. Auch bei den bodenbrütenden Anseriformes können wir beobachten, dafs die weiblichen Tiere sich in eine passende, etwa aus verrottetem Schilflaub u. s. w. bestehende Unterlage eine Mulde graben, und diese ist häufig so tief, dafs der Rücken des brütenden Vogels in gleicher Höhe mit der umgebenden Erdoberfläche ist. Die Ränder des Nestes werden dann wallartig erhöht, dadurch dafs das in der Vertiefung sitzende Tier in allernächster Nähe befindliche, d. h. also in Reichweite liegende Niststoffe mit dem Schnabel um sich herum anhäuft. Nach meiner Beobachtung fehlt nämlich allen Zahnschnäblern die Fähigkeit, Gegenstände zum Nestbau aus weiterer Entfernung herbeizuholen, und noch Niemand hat wohl eine Ente oder eine Gans etwas zu Neste tragen sehen. ${ }^{1}$ ) Diese Handlung, die wir ja von den meisten anderen Vögeln her so sehr gewohnt sind, ist bei den Anseriformes im Instinkt nicht „,vorgesehen": die Tiere müssen sich für ihr Gelege also immer einen Platz aussuchen, an dem sie, ohne erst Nestmaterial herbeibringen zu müssen, eine Mulde graben können. Häufig wird von Züchtern der Fehler begangen, Schwimmvögeln als Nistgelegenheit kleine hüttenartige Häuschen, die unten mit einem glatten Holzboden versehen sind, zu reichen. Der Erfolg ist entweder der, dafs die Tiere diese Vorrichtungen wegen des ihren Ansprüchen nicht genügenden Bodengrundes meiden, oder aber diese Häuschen werden zwar angenommen und die Eier darin abgelegt, jedoch bei den Bemühungen des Vogels, eine Mulde herzustellen und die weg-

1] Manche Enten, ferner Gänse und namentlich die Schwăne haben die Gewohnheit, besonders in der Fortpflanzungszeit Halme, düńne Äste u. dergl. mit dem Schnabel zu ergreifen und hinter sich zu legen. Diese Handlung scheint mir ein Rudiment des Nestbedeckens zu sein, wird aber hăufig ganz zwecklos ausgeführt: so z. B. auf dem Wege zum und vom Nest. 
rollenden Eier unter den Körper zu bringen, zerbrechen diese bald. Stellt man derartige Hütten ohne Holzboden auf mit Laub vermischte Erde, oder füllt man sie bis zu der erforderlichen Höhe mit geeignetem Nistmaterial, so kommt die Brut in normaler Weise Zustande. In natürlichen Baumhöhles, also in alten, ausgefaulten Stämmen, findet sich nun regelmäfsig vermodertes Holz, sogenannter Mulm, hineingewehte Blätter und ähnliches, und in diesem Detritus baut die Brautente ihr Nest. Fehlen ihr diese Stoffe, so vermeidet sie die Höhle oder zerdrückt leicht die Eier.

Nach der ganzen Art der Nestsuche glaube ich nicht, dafs die Brautente (und auch die Mandarinente) sich ganz speziell für Spechthöhlen, also in Nordamerika für die Höhle des Kaiserspechtes, interessiert oder gar auf diese angewiesen ist, wenn ich auch natürlich nicht behaupten will, dafs sie Spechthöhlen nicht gelegentlich annimmt. Gerade weil unser Vogel vorwiegend alte Astknorren, Schornsteine, abgebrochene Stämme und derartiges untersucht, bin ich der Ansicht, dafs natürliche Baumhöhlen wohl für gewöhnlich seinen Nistplatz bilden. Da die Spechthöhle nach unten eine Mulde bildet, wie dies ja in den v. Berlepsch'schen Nistkästen gut nachgebildet ist, so sind hier die Eier auch wohl ohne reichliche Nestunterlage dem Zerdrücktwerden weniger ausgesetzt, wenn sich auch in verlassenen Spechthöhlen wohl immer einige Holzspäne vorfinden.

Wie schon erwähnt, werden namentlich Schornsteine von Braut- (und Mandarinenten) gern untersucht, ja, die Tiere scheinen für diese hoch und frei in die Luft ragenden, menschlichen Gebilde eine ganz besondere Vorliebe zu haben; einerlei, ob es sich dabei um gemauerte und vielleicht elegant verzierte Bauwerke oder um hohe Blechröhren handelt. Viertelstundenlang sitzen die Paare an schönen Frühlingsmorgen auf den Schornsteinen herum, immer wieder in die dunkle Tiefe spähend, selbst wenn sie dabei tüchtig beräuchert werden. Leider ereignet es sich nicht selten, wenn sich mehrere Enten zugleich für einen solchen Rauchabzug interessieren und sich dabei gegenseitig herunterzudrängen versuchen, dafs ein Stück in den schwarzen Schlund hineingerät, und, da der Vogel in dem engen Raum die Flügel nicht gebrauchen kann, entweder ins Feuer fällt und verbrennt, oder unten elendiglich verhungert. Über die Narben, bezüglich weifsen Flecke, welche ein derartiger Fall zurücklassen kann, habe ich mich ja schon anfangs geäufsert. Um nun derartige Todesfälle, die ja noch dazu stets Weibchen mit stark entwickeltem Eierstock betreffen, zu vermeiden, habe ich die besonders beflogenen Schornsteine mit Drahtgittern verschliefsen lassen.

Das Gelege der Brautente besteht für gewöhnlich aus 11 Eiern, bisweilen findet man bis 13 , dies ist jedoch verhältnismälsig selten. Sind weniger als 11 Eier vorhanden, so handelt es sich wohl fast immer um ein nicht vollständiges Gelege. 
Wird nämlich die Ente während des Legens gestört, so kommt es leicht vor, dafs sie ihre bisherige Nisthöhle aufgibt und den Rest ihrer Eier anderswo unterbringt. Brütet eine Ente beispielsweise auf 7 Eiern (s. Tafel II.), so kann man ziemlich sicher sein, dafs die ersten 4 Eier in einem anderen, von ihr verlassenen Neste liegen. Auch bei anderen Vögeln ist, glaube ich, das sogenannte ,kleine $\mathrm{Nach} g$ eleg e" häufig einfach ein Teil eines Geleges und nicht die ganze Anzahl desselben. Die Empfindlichkeit der einzelnen Brautentenweibchen gegen Störungen ist sehr verschieden. Bei manchen genügt schon ein einmaliges Verjagen aus dem Nest, um sie von diesem zu vergrämen, andere kehren jedoch trotz aller Fährlichkeiten immer wieder in dasselbe zurück.

Die Ei er selbst haben eine durchschnittliche Gröfse von etwa $54: 41 \mathrm{~mm}$, sie wiegen frisch im Mittel circa 45-50 g und sind verhältnismälsig schwer, sodafs das Gesamtgelege von 11 Eiern ungefähr dem Gewichte des mütterlichen Vogels (etwa $630 \mathrm{~g}$ im Frühjahr) nahekommt. Wenn man bedenkt, dafs diese Eiermenge in 11 Tagen hervorgebracht wird, so ist das für den Tierkörper immerhin eine recht beträchtliche Leistung. ${ }^{1}$ ) Die Farbe der Eier ist gelblichweifs, die Schale ist sehr glatt und durchsichtig und wie bei allen Enteneiern recht dünn. Die Form ist sehr wechselnd: es gibt ebensowohl rundliche als längliche, typisch eiförmige wie walzenförmige, und es ist merkwürdig, dafs in einem Gelege von ein und derselben Ente recht verschieden geformte Eier sein können. Nach Wegnahme des ersten Geleges scheinen die Eier selten, beim dritten Gelege jedoch gewöhnlich kleiner zu werden und messen dann bisweilen nur 50:39 mm.

Bei den zuerst abgelegten Eiern findet man selten Daunen erst wenn die Zahl 11 ziemlich erreicht ist, bildet sich allmählich der Daunenkranz, der gewöhnlich mit Beginn der Brut sehr dicht geworden ist. Bisweilen kommen jedoch auch fertige Gelege vor, bei denen diese wärmende Bedeckung fast ganz fehlt (s. Tafel III, Bild 1), einen Grund hierfür vermag ich nicht anzugeben. Die Daunen selbst sind weifs, im Gegensatz zu denen unserer meisten heimischen Entenarten. Weifse Daunen finden sich unter den von mir beobachteten Anatiden bei den Tadornen und Kasarka's, Nilgänsen (Alopochen), Mähnengänsen (Chenonetta) und Türkenenten, also immer bei Höhlenbrütern, es macht daher den Eindruck, als seien die braungrauen Daunen, welche den Nestern der offenbrütenden Enten durch ihre Bodenfarbe einen so grofsen Schutz gewähren, eine besondere Anpassungserscheinung. Man kann demnach wohl das pigmentlose Weifs

1) Es wiegt durchschnittlich das Ei der Stockente (950) 53; der Pfeifente (650) 43; der Schnatterente (Chaulelasmus streperus) (700) 41; der Knäckente (Querquedula querquedula) (circa 350) 24 g. Die eingeklammerten Zahlen bezeichnen die Frühjahrs-Durchschnittsgewichte der alten Weibchen. 
dieser Gebilde als das Ursprüngliche auffassen: die weifseFarbe ist bei den Höhlenbrütern nicht störend und daher erhalten geblieben.

Die Ablage der Eier erfolgt meist in den Morgenstunden, allenfalls auch noch am frühen Vormittage, und es scheint, als bliebe die Ente beim Legen der letzten Eier eines Geleges länger auf dem Nest sitzen, als bei den ersten. Einmal glaube ich auch die Beobachtung gemacht zu haben, dafs der Vogel sicb auch schon vor dem Brüten während einer sehr kalten Frühlingsnacht in der Nisthöhle aufhielt, doch will ich dies nicht mit absoluter Sicherheit behaupten. Den Tag, an welchem das Weibchen das letzte Ei legt, kann man als ersten Behrütungstag bezeichnen, und wenn man zu dieser Zeit die Eier auf ihren Entwicklungsgrad hin ansieht, d. h. sie im durchfallenden Lichte „schiert", was bei den durchsichtigen Brautenteneiern ganz auffallend leicht ist, so stellt sich heraus, dafs die erstgelegten Eier bereits eine deutliche Keimscheibe erkennen lassen: sie entsprechen also einer Bebrütungsdauer von etwa 36 Stunden, während man bei den letzten Eiern noch nicht die Spur eines Keimes erkennen kann. Trotzdem kommt unter normalen Verhältnissen das Gelege innerhalb weniger Stunden aus. Dies ist so zu erklären, dafs Eier, welche beim Beginn der Bebrütung nicht ganz frisch sind, länger zu ihrer Entwickelung brauchen, als soeben abgelegte. Diese Unterschied gleicht sich in der Natur dadurch aus, dafs der Vogel beim Legen eines jeden folgenden Eies die bereits vorhandenen immer eine zeitlang bebrütet. ${ }^{\mathbf{1}}$ )

Gewöhnlich pflegt der Erpel sein Weibchen, wenn es sich zum Zweck der Eiablage zur Nisthöhle begibt, zu begleiten. Manche Stücke sitzen dann in der Nähe auf einem Baum oder Hausdach und warten auf die legende Gattin, um dann mit ihr wieder dem Wasser zuzufliegen. Einige tun dies bis das Gelege voll ist, andere stehen bei den letzten Eiern zwar mit der Ente vom Wasser auf und streichen ihr nach, schwenken aber, wenn sie vor der Nisthöhle angekommen ist, wieder ab, und diese Begleitung hört gewöhnlich ganz auf, wenn die Ente zu brüten anfängt. Da das Weibchen beim Verlassen des Nestes meist ein und demselben Gewässer zustrebt, und sich das Männchen häufig gerade auf diesem aufzuhalten pflegt, so verbringt das Paar die Brutpause meist gemeinsam, falls der Erpel nicht wieder eine neue Liebschaft angeknüpft hat.

Beim Verlassen des Nestes bedeckt die Ente ihr Gelege mit Daunen. Ich hatte oft Gelegenheit, von einem noch später zu besprechenden Punkte aus das Verhalten eines bestimmten Weibchens während der Brutzeit sehr genau zu beobachten. Diese Ente pflegte das Gelege stets um $1 / 212$ Uhr mittags zu verlassen. Schon eine Viertel-

1) S. Heinroth: Trăchtigkeits- und Brutdauern, Zoolog. Beobachter, Jahrg. XLIX, Heft 1. 
stunde vorher wurde das Tier unruhig und fing an, Daunen vom Rande des Nestes her unter sich zu stopfen. Dabei setzte sie sich oftmals wieder hin, erhob sich wieder und brachte von neuem Daunen zwischen sich und die Eier. Das Tier tritt bei dieser Tätigkeit in der Nisthöhle einen Schritt rückwärts, sodafs der Schwanz hoch an der Wand des Kastens emporragt, und der Kopf steht dann ungefähr über der Mitte des Geleges. Nachdem alles fertig, kommt die Ente in den Eingang der Höhlung (s. Tafel I, Bild 7) und streicht nun sofort ab. Bei allen Manipulationen im Neste ist das Tier mit den Eiern sehr vorsichtig und tritt möglichst so auf, dafs die Beine nicht auf die Eier, sondern seitlich von ihnen auf den Nestrand aufgesetzt werden.

Die Zeit, welche vergeht, bis das Brautentenweibchen zum Neste zurückkehrt, ist verschieden, man kann im allgemeinen sagen, dafs die Brutpause etwa $1 / 2-1$ Stunde beträgt. Inzwischen kann man alle nötig werdenden Hantierungen im Neste ausführen, also namentlich die Eier schieren, ohne dafs die Ente bei ihrem Wiederkommen etwas davon merkt. Von verschiedenen Seiten wird behauptet, dafs ein Vogel es unter allen Umständen wahrnehmen könne, wenn seine Eier vom Menschen berührt worden sind, und diese dann gewöhnlich verlasse: wie oft habe ich die Nester unserer Grasmücken und vieler anderer Vögel berührt, die Eier herausgenommen und geschiert, und niemals ist es mir vorgekommen, dafs das Paar das Nest aufgegeben hat. Nicht das Berühren ist es, das der Vogel merkt, sondern die Veränderung des Nestes und seiner Umgebung, die von ungeschickter Hand oft unbeabsichtigt herbeigeführt wird.

Es sei noch erwähnt, dafs das Entenweibchen niemals die Eier bedeckt, wenn es durch Störungen veranlafst das Nest verläfst. Selbst wenn das Tier das Herannahen eines Menschen schon von weitem gewahr wird und aus Erfahrung weifs, dafs es nun bald vom Neste verjagt werden soll, denkt es nie daran, für den Kälteschutz des Geleges Anstalten zu treffen. Wird die Ente vom Neste gescheucht, ohne dafs der Ruhestörer sich nachher längere Zeit an der betreffenden Stelle aufhält, sondern sich sofort wieder entfernt, so kommt sie nicht etwa gleich wieder zurück, um für ihr Gelege zu sorgen, sondern verbindet mit dem Abfliegen gewöhnlich eine längere Brutpause, badet und putzt sich, sucht nach Nahrung u. s. w. Inzwischen liegen die Eier vollkommen unbedeckt, was ihnen übrigens auch meist nichts schadet. Alles dies deutet darauf hin, dafs das einzelne Individuum gar keine Ahnung von dem eigentlichen Zweck des Eierbedeckens hat, und dafs nur die Unruhe, welche das Tier schon eine Weile vor der täglichen Brutpause erfalst, instinktiv zu dem Zudecken des Geleges führt.

Die Empfindlichkeit gegen Störungen während der Brutzeit ist ebenso wie die während der Zeit der Eiablage individuell sehr verschieden. Für gewöhnlich verhält sich die Sache so, dafs 
die Ente bei der allerersten Beunruhigung recht fest sitzt. Man kann dann häufig tüchtig an den Stamm klopfen und eine Leiter an den Baum legen, ohne dafs der Vogel auch nur aus der Öffnung herausschaut. Anders, wenn das Tier schon häufiger schlechte Erfahrungen gemacht hat, denn die Ente lernt rasch nach dem Gehör unterscheiden, welche Vorgänge aufserhalb der Nesthöhle für sie bedeutungsvoll sind, und manche Exemplare verlassen ihr Gelege schliefslich schon bei der geringsten Störung. So brütete z. B, ein Brautentenweibchen in einem Kasten, der an einem Baum auf einer Insel $3 \mathrm{~m}$ hoch über der Erde etwa aufgehängt war. Die Insel liegt nahe am Ufer und ist mit diesem durch ein schmales Laufbrett verbunden. Das Flugloch der Nisthöhle ist nach der Mitte des Teiches zu gerichtet, so dafs die brütende Ente das Laufbrett, sowie die ganze Gegend nach der betreffenden Uferseite zu, nicht sehen kann. Nach ganz kurzer Zeit nun war es auch mit äufserster Vorsicht nicht mehr möglich, den Steg zu betreten, ohne dafs die Ente abstrich, oder wenigstens zum Abfliegen bereit war. Ich mufs sagen, dafs es mir heute noch unerklärlich ist, wie der Vogel auf eine Entfernung von etwa $9 \mathrm{~m}$ in oft recht geräuschvoller Umgebung das Aufsetzen eines Fufses auf das Brett hören konnte, zumal zwischen dem Nistkasten und dem Ufer ein dicker Baum und Gebüsch sich befinden. Einzelne Enten, besonders zahme Stücke, sitzen übrigens auch nach wiederholten Störungen sehr fest, sodafs man an den Nistkasten selbst klopfen mufs, um die Tiere zum Verlassen desselben zu bewegen.

Beim Brüten sitzt der Vogel gewöhnlich mit ganz eingezogenem Halse, dabei sind die Augen oft halb, manchmal auch ganz geschlossen, sodafs die Brüterin häufig zu schlafen scheint. In hoher Luft umherziehende Mauersegler und andere Vögel werden bisweilen aufmerksam betrachtet, und $a b$ und zu putzt sich der Vogel ein bischen im Gefieder herum. Auch habe ich mich bisweilen gewundert, wie es eine Ente an drückend heifsen Junitagen um die Mittagszeit in einer Höhle, welche ganz frei nach Süden liegt und der Sonnenglut direkt ausgesetzt ist, zwischen ihrem dichten Daunenkranze vor Hitze aushält; denn für gewöhnlich findet man, dafs Wasservögel nicht gerade übermälsig wärmeliebend sind. Ich habe unter solchen Umständen jedoch nicht einmal beobachten können, dafs das Tier den Schnabel aufsperrt, wie dies Vögel, denen es zu heifs wird, sonst stets zu tun pflegen. Auch sei bemerkt, dafs derartig heifs und trocken gelegene Nisthöhlen keine schlechteren Brutergebnisse aufweisen, als kühl und schattig hängende,

Sehr fest sitzt die Ente während des Ausschlüpfens der Jungen oder wenn dieses unmittelbar bevorsteht: dann mufs man auch bei scheueren Stücken schon recht nahe kommen, um sie zum Verlassen des Kastens zu bewegen.

Die Brutdauer der Brautente beträgt 31 Tage, also 5 Tage mehr, als die der Stockente. Diese auffallend lange Zeit 
wird verständlicher, wenn wir bedenken, dafs höhlenbrütende Enten anscheinend stets länger brüten, als die freinistenden Gattungsverwandten. Ich erinnere daran, dafs die ja allgemein domestizierte Türkenente (Cairina), auch eine Höhlenbrüterin, zur Zeitigung ihrer Eier sogar 35 Tage bedarf.

Ich erkläre mir dies Verhalten so, dafs die Embryonen der Höhlenbrüter sich eine so lange Entwicklungszeit ,leisten können“, weil die Zuchtwahl nicht auf eine Beschleunigung der Entwickelung hinwirkt. Da unsere Vögel in ihren Baumhöhlen vor sehr vielen tierischen Feinden und vor allen Dingen vor den so viele Entengelege zerstörenden Überschwemmungen sicher sind, so kommt es nicht so sehr darauf an, ob die Tiere ein paar Tage länger oder kürzer brüten. Genau umgekehrte Verhältnisse finden wir dagegen bei hochnordischen Anseriformes. Hier mufs die ganze Fortpflanzung bis zum Flugfähigwerden der Jungen während der 3 Sommermonate erledigt werden: hier ist jeder Tag kostbar, und so kommt es denn, dafs $z$. B. die Pfeifente ( $M$. penelope), die an Körpergröfse die Brautente noch etwas übertrifft, nur 22 Tage brütet. Hier kann man wohl mit Sicherheit annehmen, dafs eine ehedem lange Brutdauer durch die intensive Zuchtwahl äufserer Faktoren auf $2 / 3$ der ursprünglichen Zeit abgekürzt wurde.

Bereits am zweiten Bebrütungstag ist die Keimscheibe beim Schieren des Eies deutlich zu erkennen, und etwa gegen den 5. Tag hin sind die embryonalen Blutgefäfse wahrnehmbar. Am 29. Tage pflegen die Eier ,gepickt" zu sein, und dann vernimmt man deutlich das Ficken des Schnabels und häufig auch ein leises Piepen im Innern derselben. Die Pickstelle vergröfsert sich, wie wohl bei den meisten Vögeln, in den ersten Stunden nicht. Dann aber am 30. Tage arbeiten die jungen Enten weiter, und man sieht den Erfolg in Gestalt eines vom stumpfen Pole etwa um $1 / 3$ der Länge des Längsdurchmessers entfernten, ringförmigen Durchbruches. Dieser „Breitengrad“ ist am 31. Tage in seiner ganzen Länge von innen durchgestofsen, und die junge Ente verläfst in der gewöhnlichen Weise durch Abheben der stumpfen Kalotte das Ei.

Um mir Gel̄egenheit zu verschaffen, den ganzen Vorgang des Nestsuchens, des Brütens und Ausführens der Jungen zur unmittelbarsten Anschauung $\mathrm{zu}$ bringen und alle diese Phasen photographieren zu können, hatte ich folgende Vorkehrungen getroffen. $2 \mathrm{~m}$ vor der Dachluke eines unbewohnten Hauses wurde auf einer Stange ein Entennistkasten angebracht, sodafs ich vom Dachboden aus den ganz frei nach Süden stehenden Nistkasteneingang direkt vor mir hatte. Die Dachluke selbst vernagelte ich bis auf einen kleinen Spalt für das photographische Objektiv und ein kleines Guckloch, vollkommen. Aufserdem verdunkelte ich den Bodenraum, sodafs mein Aufenthalt darin von den am Nistkasten befindlichen Enten nicht wahrgenommen werden konnte. Das Flugloch des Nistkastens befand sich $9 \mathrm{~m}$ 
über der Erde, etwa $1 \frac{1}{2} \mathrm{~m}$ über der Dachrinne des Hauses, cr. $0,5 \mathrm{~m}$ von letzterem und $2,05 \mathrm{~m}$ von der photographischen Linse entfernt. Dieser aus einem hohlen Birkenstamm hergestellte Nistkasten ist es, der auf unseren photographischen Aufnahmen auf Tafel I sichtbar ist, seine Gesamthöhe beträgt $63 \mathrm{~cm}$, sein äufserer Querdurchmesser $30 \mathrm{~cm}$, der Höhendurchmesser des Flugloches $20 \mathrm{~cm}$, der gröfste Querdurchmesser desselben $9,3 \mathrm{~cm}$.

Sehr störend für das Fhotographieren ist es, dafs die Nestsuche in die allerersten Morgenstunden fällt. Nach $8 \mathrm{Uhr}$ hat man selten noch das Glück, Enten anzutreffen, und auch um diese Tageszeit pflegt im April das Licht für Momentaufnahmen noch recht schwach zu sein, zumal man doch im Frühling mit recht vielen trüben, bezüglich Regentagen $\mathrm{zu}$ rechnen hat.

Die Bilder No, 2, 3 und 4 auf Tafel I, welche die Nestsuche darstellen, zeigen, wie an den weiblichen Vögeln leicht zu erkennen, nicht immer dasselbe Paar, denn der Kasten wurde von recht vielen Enten besucht. Ein schliefslich zu Stande gekommenes Gelege war anscheinend von einer Mandarinente zerstört worden, und ich hatte es schon aufgegeben, eine Brut an dieser Stelle beobachten zu können, als ich zufällig bei einem Gange durch den Garten aus der betreffenden Richtung her um die Mittagszeit ein Brautentenweibchen fliegen sah, das mir nach seinem ganzen Verhalten den Eindruck machte, als komme es von seinem Gelege. Es stellte sich denn heraus, dafs der "Photographiernistkasten" ganz im Stillen - die Tage waren inzwischen länger geworden und demzufolge die neue Nestsuche und das Eierlegen in sehr frühe Morgenstunden gerückt - mit einem neuen Gelege beschickt worden war, das schon einige Tage der Bebrütung hinter sich hatte. Ich konnte nun die brütende Ente noch fast 4 Wochen lang in aller Ruhe beobachten, und es war mir schliefslich auch möglich, das Verhalten der jungen Enten im Nest, sowie ihr Herausspringen aus demselben eingehend $\mathrm{zu}$ studieren, bezüglich zu photographieren. Ich habe während dieser Zeit die Ente bei ihrem Brutgeschäft oft nicht gerade beneidet: wir hatten damals wohl die heifsesten Tage des Jahres 1909, das meine Dachluke schützende Blech wurde unter den Sonnenstrahlen so heifs, dafs man es nicht mehr berühren konnte, und dabei schien die Mittagssonne in das genau nach Süden liegende Einflugsloch, der Ente direkt auf den Rücken!

Nachdem die Jungen a u s gek rochen sind, liegen sie zunächst noch ziemlich still zwischen den Eierschalen (Tafel III, Bild 1) unter der Mutter, und es dauert einige Stunden, bis sie ganz abgetrocknet sind und die Hüllen der Primärdaunen ziemlich verloren haben. Oft erhebt sich die Ente, sieht unter sich, setzt sich wieder hin, dreht sich um sich selbst, und man sieht schon bisweilen ein oder das andere Junge wenigstens mit dem Kopf auf dem Rücken der Mutter erscheinen. In meinem „Photographiernistkasten" konnte ich deutlich erkennen, wie der feine, kleien- 
artige, von den abgeriebenen Daunenhüllen herrührende Staub sich überallhin verteilte: die Mutter sah schliefslich ganz bepudert aus und rieb sich häufig Kopf und Schnabel auf dem Rücken, um den lästigen Staub aus Augen und Naslöchern zu entfernen. Am Vormittag war anscheinend das Auskriechen erfolgt, und ich war darauf gefafst, dafs bereits am Nachmittage die Familie das Nest verlassen würde, sodafs ich es nicht wagen wollte mich aus meiner Dachkammer zu entfernen. Da wurde ich abends zwischen 6 und $7 \mathrm{Uhr}$ abgerufen, und als ich nach wenigen Minuten wieder auf meinem Beobachtungsposten erschien, konnte ich von dem lebenden Nestinhalt nichts mehr gewahren und glaubte natürlich, die Alte habe während meiner Abwesenheit ihre Kinderschar ausgeführt und suchte nun die ganze Umgegend nach ihr ab. Ich hatte die Sache schon aufgegeben, sah aber nach etwa einer halben Stunde noch einmal aus meinem Guckloch und - die Fnte safs wieder auf ihren Jungen! Sie hatte also wohl wegen des Ausschlüpfens der Eier ihre gewöhnliche Mittagsbrutpause auf den Abend verlegt, die Jungen aber hatten, weil sie noch nicht kräftig genug waren, nach dem Abstreichen der Alten die Nisthöhle nicht verlassen, waren aber, wegen der Tiefe des Kastens für mich unsichtbar geblieben. Da die allmählich eintretende Dunkelheit ein weiteres Beobachten und namentlich ein Photographieren nicht mehr gestattete, so erschien ich erst am nächsten Morgen wieder in meiner Dachkammer und gewahrte zu meiner Freude, dafs sich das Bild noch nicht verändert hatte: unruhig liefen einige Entchen auf dem Rücken der Alten herum und pickten ihr ab und zu in die glänzenden Augen.

Eine merkwürdige Beobachtung machte ich: Schon bald nach dem A usschlüpfen der Jungen entnahm die Alte häufig Fett aus ihrer Bürzeldrüse und riebsich damit die Unterseite e in. Dies wiederholte sich in kurzen Abständen, so lange sich die Mutter mit ihren Kindern in der Nisthöhle befand, während des Brütens hingegen hatte sie dieses Einfetten niemals vorgenommen. Es ist ja bekannt, dafs die Entchen, die von der Ente erbrütet sind, sofort nach dem Verlassen des Nestes wasserfest sind: siegehen ja dann gleich mit der Mutter in das feuchte Element und schwimmen und tauchen ohne wesentlich benetzt zu werden. Im Gegensatz dazu mufs man mit von der Henne ausgebrüteten Jungenten vorsichtiger sein, denn diese werden auf dem Wasser leicht nafs, und man kann sie zunächst nur für kürzere Zeit hineinlassen. Schon lange schrieb man den grö fseren Fettgehalt der Daunen der von einer Ente erbrüteten Jungen dem Umstande $\mathrm{zu}$, dafs die kleinen Dinger bei ihrem Umherkrabbeln sich an dem fettigen Gefieder der Mutter reiben: néu ist mir aber die Tatsache, dafs die alte Ente in dieser Zeit sich fortwährend einfettet. Auch ihre Oberseite vergifst sie dabei nicht ganz, sodafs die Nachkommenschaft, wenn sie auf dem Rücken der Alten umherhuscht, sich die Unterseite einölt. 
Etwa gegen $63 / 4$ Uhr morgens begann die alte Ente aus dem Kasten zu sehen, und kurz darauf strich sie ab, ohne jedoch den „Huäk"-Lockton auszustofsen, ich hörte nur das bekannte, aber etwas abgeänderte „Tĕtĕtĕtĕt". Das Tier war nicht in der üblichen Richtung davongeflogen, die es sonst einschlug, wenn es während des Brütens das Nest verliefs, sondern es schien mir direkt dem Boden zuzustreben, sodafs es sich wohl auf der Erde unter dem Nistkasten aufhalten mufste; genaueres konnte ich nicht sehen, da ich durch mein Guckloch in der Bodenkammer nur ein kleines Gesichtsfeld vor mir hatte. Unmittelbar darauf erschien ein Junges im Nesteingang, und einen Augenblick später hörte ich es vor mir auf das Dach autschlagen. Dann folgten zwei, dann wieder einige, und im Verlauf von vielleicht dreiviertel Minuten war das Nest leer. So schnell es ging, photographierte ich (s. Tafel I, Bild 6), aber so sehr ich mich auch beeilte, mehr als drei Aufnahmen, von denen allerdings 2 als vollkommen gelungen zu bezeichnen sind, konnte ich in der Zeit, welche die acht Jungen brauchten, um ihr Nest $\mathrm{zu}$ verlassen, nicht fertig bringen. Gern hätte ich auch die kleinen Dinger während ihrer eigentlichen Luftreise photographiert, aber ein Gewitter verdunkelte den Himmel, und der Momentverschlufs mufste deshalb langsamer gestellt werden, als es für diese schnelle Bewegung notwendig gewesen, wäre. Das Herausspringen selbst geschieht in der Weise, dafs die kleinen Enten einen Augenblick im Eingang stehen und dann einen tüchtigen Hoch- und Weitsprung vornehmen. Sie kommen also, wie von unsichtbarer Gewalt geworfen, in hohem, weiten Bogen aus dem Kasten heraus.

So viel ich hören konnte, gelangten einige direkt auf die Erde, die meisten endeten vor mir auf dem Dache meines Beobachtungshauses, liefen da ein Weilchen hin und her und sprangen dann über die Dachrinne nach unten, eins geriet sogar in den absteigenden Teil der Rinne, und ich mufste es, durch das Gehör auf seinen Aufenthalt aufmerksam gemacht, durch Abschrauben des unteren Teiles des Blechrohres retten. Sobald ich kein Entchen mehr von meiner Luke aus gewahrte, eilte ich nach unten und fand einige Schritte vom Hause entfernt die Familie bereits versammelt vor, bis auf 2 Stück, welche auf dem Wege zur Mutter hinter ein Stück Drahtgeflecht geraten waren und sich dort festgelaufen hatten, und das eine an dem Rohre. Um die Fehlenden schien sich die Alte nicht weiter zu kümmern, als sie mit den 5 bei ihr befindlichen Kleinen den Weg nach dem Teiche einschlug.

Da aus den, im Eingang meines Aufsatzes erwähnten praktischen Gründen eine Aufzucht der kleinen Dinger durch die

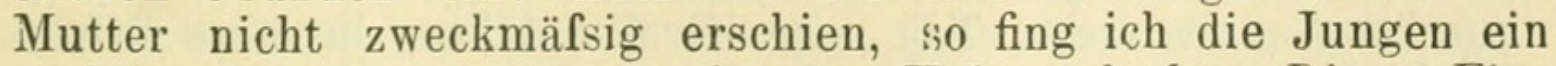
und brachte sie zu einer geeigneten Hühnerglucke. Dieses Einfangen ist nicht ganz einfach, denn die kleinen Enten sind sehr schnell zu Fufs und, wenn sie sich drücken, schwer zu finden. Es gelang aber durch vorsichtiges, langsames Treiben die Familie 
in einen Schuppen zu dirigieren, woselbst das Ergreifen der Jungen gut von statten ging. Setzt man ein solches Entchen auf die Erde, so „drückt es sich" häufig, durch die Anwesenheit des Menschen erschreckt, indem es sich der Länge nach mit vorgestrecktem Kopf und Halse niederlegt, und verharrt dann vollkommen regungslos. Zu diesem Verhalten ist die Anwesenheit oder die Warnstimme des alten Vogels nicht nötig, sondern das Junge reagiert von selbst, wenn es Menschen sich nähern sieht, in der angegebenen Weise.

Das bekannte "sich Verstellen" der kleine Junge führenden Mutterente bei Gefahr, das ja darin besteht, dafs die Alte scheinbar flügellahm vor dem Feinde herflattert, um diesen vor der Nachkommenschaft abzulenken, trat in diesem Falle nicht ein, man macht nämlich die Erfahrung, dafs solche Enten, die an den Anblick des Menschen sehr gewöhnt sind, wie dies ja bei Parktieren stets der Fall ist, solche Verstellungskünste nicht üben. Zur Auslösung dieses Verstellungsinstinktes gehört offenbar das Eintreten eines sehr grofsen Schreckes, und ein solches Entsetzen ruft der Mensch bei einem zahmen Vogel nicht mehr hervor. Unter gewissen Umständen tritt der Verstellungsreflex übrigens doch noch ein, namentlich, wenn man die Familie recht plötzlich überrascht, sie also nicht langsam treibt, sondern heftig jagt oder mit Kähnen zwecks Einfangens der Jungen hinter den Tieren her ist.

Das Herausspringen der jungen Brautenten aus der Nisthöhle habe ich nun nicht nur bei dem "Photographiernistkasten", sondern auch sonst noch des öfteren beobachtet. Es findet gewöhnlich in den ersten Vormittagsstunden, etwa zwischen 7 und 10 Uhr statt, und ich habe auch schon erlebt, dafs erst einige Minuten vergingen, bis die Jungen herunterschlüpften, nachdem die Mutter das Nest verlassen hatte. Viel merkw ürdiger als das Herunterspringen schein tmir das Erklimmen der Innenwand der Nesthöh le bis zum Flugloch zu sein. Nicht immer beträgt der Abstand zwischen dem Nest und der Höhlenöffnung nur wenige Centimeter, er kann bei natürlichen Baumhöhlen auch ganz beträchtlich gröfser sein. Die Wand ist gewöhnlich fast senkrecht, und wenn auch nicht immer absolut glatt, so doch mit nur geringen Unebenheiten versehen. Um dieses hohe Hindernis zu überwinden, ist die junge Brautente nun mit nadelspitzen Krallen ausgestattet, die kräftig eingeschlagen werden können, und die Tiere sind tatsächlich im Stande, an senkrechten, ja überhängenden Brettern nach Spechtart, aber ohne Zuhülfenahme des Schwanzes, in die Höhe zu klettern. Man kann sich davon leicht überzeugen, wenn man erst einen Tag alte Brautentchen in eine Kiste oder hinter ein engmaschiges Drahtgeflecht setzt: sie wandern dann in kurzer Zeit über diese Dinge hinweg und verschwinden sogar aus ziemlich hoch über dem Boden gelegenen Fenstern u. dergl. Diese Fähigkeit besitzen die Tiere nur in den aller- 
ersten Lebenstagen, nur dann ist sie ja unter normalen Umständen für die jungen Enten von Wichtigkeit, und später werden die Vögel bald zu schwer für solche Kletterpartien. Aufser der Brautund Mandarinente kommt diese Eigenschaft von den bekannteren Schwimmvögeln noch der ebenfalls höhlenbrütenden Türkenente (Cairina) zu. Wie ich von Augenzeugen gehört habe, brütet die letztere Art in der Freiheit bisweilen in mehreren Meter tiefen, senkrecht nach unten gehenden Höhlen, sodafs die Jungen etwa ein Stockwerk hoch im Innern heraufwandern müssen! Dafs im Gegensatz dazu junge Stockenten, die ja für gewöhnlich nicht in Baumhöhlen ausgebrütet werden, nicht so kletterfähig sind, geht aus folgender Tatsache hervor. In den im Berliner Tiergarten für die Brautenten dankenswerterweise zahlreich aufgehängten Kästen waren auch einzelne Stockenten zur Brut geschritten, und man fand später bei der Durchsicht der Nisthöhlen neben den Eierschalen eine Anzahl verendeter Jungenten. Wahrscheinlich hatten sich, bei dem Versuch das Nest zu verlassen, die Jungen alle unter dem Höhlenausgang zusammengedrängt, und einige, ihre dort versammelten Geschwister als Leiter benutzend, hatten zum Flugloch gelangen können, den übrigen war dies nicht möglich gewesen, und sie sind dann elendiglich zu Grunde gegangen. Wie ich beim Kapitel „Nestbau“ schon gezeigt habe, ist im Entenhirn ein Centrum für Lokomotion von Gegenständen bei der Ente anscheinend nicht vorhanden, die Mutter kann also nicht auf den Gedanken kommen, die Jungen herunterzutragen oder sie aus dem Flugloch herauszuwerfen. ${ }^{\mathbf{1}}$ ) Dafs ein Vogel jemals bis zu der Überlegung kommt, dafs er selbst zur Leiter für seine Jungen dienen kann, indem er sich dicht an dem Flugloch in das Nest setzt, halte ich für vollkommen ausgeschlossen, und die Tatsachen beweisen dies auch.

Ich habe niemals bemerkt, dafs sich die jungen Entchen bei ihrem "Sprung ins Leben" verletzt haben, einerlei, ob sie dabei auf die flache Erde, ins Gesträuch, auf den Rasen oder ins Wasser fielen. Und wenn man sich die Anatomie eines

1) Im „Neuen Naumann“ werden die verschiedenen Arten zusammengestellt, wie die Stockente ihre Jungen vom hochgelegenen Nest herabbringen soll. Die meisten Autoren geben ein Herabspringen an, einige meinen, die Alte trage die Jungen, sie am Halse ergreifend, herunter, wieder einer läfst sie zwischen den Füfsen der Mutter die Luftwanderung antreten, nach der vierten Ansicht klemmt die Alte ihre Spröfslinge unter das Kinn, und ein Fünfter gibt. an, dafs Mutter Stockente die Kinder aus dem Neste wirft. Warum verfielen unsere Tiergarten-Stockenten nicht auf diese Auswege, für die übrigens kein Berichterstatter Photographien oder sonstige Belege gibt? Ich mufs offen bekennen, dafs ich solche Angaben, die zur Erreichung ein und desselben Zieles verschiedene Wege für möglich halten, nicht recht glaube: durch ibren Instinkt steht der Ente wohl nur ein Weg zur Lösung einer Aufgabe offen. 
solchen Dunenbällchens klar macht, so wird man finden, dafs an dem kleinen Ding eben nicht viel Verletzbares ist. Eine neugeborene Brautente wiegt etwa 20-24 g (Gewicht des Buchfinken, Feldsperlings und der Nachtigal) ${ }^{1}$ ), ihr Körper ist sehr klein, und ihre scheinbare Gröfse wird durch die dichten, langen und ungemein elastischen Daunen bewirkt. Die Flügel sind nur erst andeutungsweise vorhanden, ein Brustbeinkamm, sowie die dazu gehörigen, beim erwachsenen Vogel sonst so entwickelten Brustmuskeln fehlen noch so gut wie vollständig (s. Tafel IV, Bild 1 und zum Vergleich den ebenso alten Fasan auf Bild 2). Es kommen also für eine Bruchverletzung (Fractur) eigentlich nur die Beine in Betracht, da aber die Gelenke derselben noch nach allen Richtungen hin recht nachgiebig sind, so ist auch hier keine Beschädigung $\mathrm{zu}$ befürchten und kommt auch erfahrungsgemäfs recht selten vor.

Wenn behauptet wird, dafs eine herabspringende Jungente die Wucht ihres Falles durch die Flügelmildere, so beruht dieser Ausspruch auf einer grofsen Verkennung der Wirklichkeit, bezüglich des anatomischen Verhaltens, weil, wie bereits bemerkt, die Brustmuskeln so gut wie gänzlich fehlen. Da der Flügel im Verhältnis zum Körper ungemein klein, er auch nur mit weichen Daunen besetzt und seine aktive Beweglichkeit fast gleich Null ist, so wird der Widerstand, welchen er der Luft zur Minderung der Fallgeschwindigkeit darbieten mürste, ganz illusorisch.

Überläfst man die Familie ganz sich selbst, so führt die Alte ihre Jungen sofort einem Gewässer zu und ist leider in der Auswahl desselben oft recht unvorsichtig. Im allgemeinen kann man sagen, dafs sie den Teich mit Vorliebe aufsucht, auf dem sie sich auch sonst am meisten aufgehalten hat. Für die freie Wildbahn wird dies ja auch ganz zweckmässig sein, denn wo sich eine Ente häufig aufhält, da findet sie auch Futter und Deckung, sie hat also dort eine gewisse Existenzsicherheit, und die Wahrscheinlichkeit, dafs auch die jungen Enten dort gut gedeihen, ist ziemlich grofs. Für unseren Zoologischen Garten dagegen liegen die Verhältnisse ganz anders. Da ist z. B. eine Brautente, die eine besondere Vorliebe für einen kleinen Teich hat, dessen Ufer vollkommen aus Cementfelsen bestehen, und auf dem sich grofse Möwen, Kormorane und Pelikane tummeln. Weil dort ein einzelner, wegen seiner grofsen Unverträglichkeit dahin verbannter Schwan sein Körnerfutter erhält, so hat die Ente den Tisch hier stets gedeckt gefunden, und, da sie im Gegensatz zu den sonstigen amputierten Teichbewohnern flugfähig ist, sich

1) Dafs, wie im „Neuen Naumann" aus „Collet" citiert wird, junge Stockenten 6,5 g, junge Krickenten $1,44 \mathrm{~g}$ wiegen sollen, sind wohl zwei Druckfehler, erstere wiegen circa $30-35 \mathrm{~g}$, bei letzteren scheint das Komma um eine Stelle zu weit nach vorn geraten zu sein! 
auch gut vor den Angriffen dieser Tiere retten können. Als sie nun im Frühjahr ihre eben erbrüteten Jungen ausführte, lag ihr ein zur Aufzucht sehr günstiger Teich am Wege, sie ging auch für kurze Zeit auf denselben, wanderte dann aber über Land ihrem geliebten Pelikanteiche zu, und, unterwegs durch Gewalt von ihrem Vorhaben abgebracht, unternahm sie ihre Wanderung doch bald wieder, und es gelang mir erst kurz vor ihrem Eintreffen auf dem gefährlichen Gewässer die Jungen einzufangen und einer Pflegemutter zu übergeben. Die kleinen Dinger hätten sonst gar bald ihr Grab im Magen eines ewig hungrigen Fischräubers gefunden oder wären in kurzem verhungert, da irgend welche Insektennahrung in dem cementierten Teiche natürlich nicht vorhanden war: dies nur ein Beispiel, von denen ich leicht mehrere erzählen könnte. Nicht nur Brautenten handeln so, sondern in ganz derselben Weise verfahren auch Stockentenmütter: sie führen ihre Jungen häufig ins sichere Verderben, obgleich dicht daneben ein insektenreicher und zur Aufzucht von Jungenten durchaus geeigneter Tümpel liegt. Die alte Ente hat offenbar garkeine Vorstellung davon, dafs ihre Jungen fressen wollen und wovon sie sich ernähren; in den meisten naturgeschichtlichen Abhandlungen vermissen wir aber wohl selten den Passus: „sie führt sie einem nahrungsversprechenden Gewässer zu"!

Wenn eine Ente zur Aufzucht für ihre Nachkommenschaft wirklich einmal einen geeigneten Platz findet, so kann man sie natürlich auch ihre Jungen dort selbst führen lassen, man macht aber die Beobachtung, dafs sich die einzelnen Individuen dabei sehr verschieden gut bewähren. Da gibt es Enten, die ruhelos im Geschwindtempo den ganzen Teich durchrudern. Sie lassen ihren Jungen keine Zeit zur Nahrungssuche oder zum Ausruhen, vergessen die zurückbleibenden Stücke, und es dauert nicht lange, so haben sie ihre ganze Brut oder wenigstens einen grofsen Teil derselben „zu Tode geführt" oder besser gesagt: gehetzt. Dies gilt übrigens nicht nur für Lampronessa, sondern auch für viele andere Entenarten: mir scheint es dabei so, als wenn sich die Entenmutter auf dem betreffenden Gewässer nicht recht sicher fühlt. Besser gestaltet sich die Sache, wenn sich die Alte bald ruhig ans Ufer setzt, die Jungen unternimmt, „hudert", wie man zu sagen pflegt, und dann langsam die Uferränder absucht, den Jungen Zeit lassend, zwischen Wasserpflanzen und Rohr nach Insekten $\mathrm{zu}$ jagen.

Das Heranwachsen der jungen Brautenten bei ihrer Mutter verläuft in derselben Weise, wie bei anderen Schwimmenten. Ist viel Nahrung vorhanden und das Wetter warm, so halten die Kleinen gut zusammen und sind dann die schon geradezu sprichwörtlich gewordenen ,folgsamen Entenküken". Anders aber, wenn kühle Tage eintreten, die Insektenmangel zur Folge haben, oder wenn auf dem Gewässer sich aus anderen Gründen zu wenig Nahrung für die Jungen findet: dann zerstreuen sie sich leicht, 
fallen dem Raubzeug zum Opfer oder verkommen schliefslich vor Kälte oder durch Hunger in einem Winkel. Das letztere findet häufiger statt, als gewöhnlich angenommen wird. Trotzdem wir im Berliner Zoologischen Garten nicht gerade über Rattenmangel zu klagen haben, so sind diese Nager durchaus nicht immer am Verschwinden der Kleinen schuld, denn gar häufig findet man in einer Ecke ein totes, abgekommenes Entchen, das keinerlei Verletzungen zeigt.

Nach vielen Beobachtungen bin ich zu der Überzeugung gekommen, dafs eine Mutterente von der Anzahl ihrer Kinder keine Ahnung hat. Sie ist zufrieden, wenn sie mit einem Jungen herumschwimmt, und kümmert sich nicht im geringsten um die übrigen Stücke, falls sie diese nicht hört oder sieht, und leider passiert es deshalb gar oft, dafs sie mit einigen wenigen weiterzieht, während die anderen unbemerkt zurückbleiben. Anders liegt es natürlich, wenn sie das Piepen, speziell das ängstliche Locken ihrer Kinder hört, dann macht sie Halt oder schwimmt auch wohl nach der betreffenden Richtung hin. Häufig aber ist die Entfernung schon zu grofs, das kleine Ding zu matt, und das Jungentchen hat das Verpassen des Anschlusses mit dem Tode zu büfsen. Da ich die Eigenschaften der einzelnen Ente als Führerin natürlich im Voraus nicht kenne, so bin ich auf den Ausweg verfailen, dafs ich der Mutter eine ganz geringe Anzahl, etwa ein bis drei Junge lasse, die anderen aber am besten gleich nach dem Ausschlüpfen wegnehme und einer Henne unterschiebe. Eine gewisse Schwierigkeit ist auch die, dafs, wenn mehrere ganz kleine Junge führende Brautenten weibchen auf einem Teiche sind, diese sich über ihre eigenen Kinder unklar werden und dabei oft die eigenen Spröfslinge im Stich lassen, um sich zu irgend einem anderen Jungentchen zu begeben, das sie garnichts angeht. Am gröfsten ist diese Gefahr in dem Zeitpunkte, wenn die Familie gerade den Nistkasten verlälst, die einzelnen Angehörigen kennen sich dann noch nicht recht, und die Mutter schliefst sich nach dem Verlassen der Nisthöhle leicht anderen Entchen an, während die eigene Brut suchend umherirrt.

\section{Psychisches Verhalten.}

Wie ich im Vorhergehenden gezeigt habe, ist das Leben der Brautente, und überhaupt der Anatiden, sehr reich an komplizierten Instinkten, es werden also von allen Angehörigen der Art eine grofse Anzahl Handlungen ausgeführt, die nicht von dem einzelnen Tier erst gelernt sind. lch erinnere an die Nestsuche, bei der, wie schon erwähnt, der Vogel ja nach etwas sucht, von dessen Vorhandensein er keine Ahnung haben kann, an das Einfetten der alten Ente in der Zeit, in welcher sie mit den Jungen in der Nestmulde sitzt, und vieles andere.

Ich möchte unter Intelligenz im folgenden die Verwertung der vom Individum erworbenen Erfahrungen 
verstanden wissen und wende das Wort also in ganz anderem Sinne an, als Wafsmann es tut.

Der jungen Brautente ist, wie jeder anderen Wildente und auch den meisten Hausenten eine ziemliche Schreckhaftigkeit angeboren: vor allen grofsen, sich bewegenden Dingen fürchtet sie sich, auch wenn sie noch keine schlimmen Erfahrungen mit dem betreffenden Gegenstande gemacht hat. Auch im Brutapparat ausgekommene Brautenten drücken sich beim erstmaligen Ansichtigwerden des Menschen entweder unbeweglich in die Ecken oder überspringen eilends den Rand des Kastens und sausen wie die Mäuse im Zimmer herum, um sich schliefslich unter irgend einem Gegenstande zu verstecken. Diese Scheu legen sie in ganz kurzer Zeit, ja schon in einigen Stunden ab, aber natürlich nur, wenn die ganze Situation unverändert bleibt: an einen neuen Ort versetzt oder unter sonst anderen Bedingungen tritt die frühere Ängstlichkeit sofort wieder ein. Sie gewöhnen sich meist schnell an eine Henne und folgen dieser gut. Wie wohl alle jungen Enten lernen sie in einigen Tagen auch die Futterlockstimme der Glucke kennen und kommen herbei, wenn die Henne in der bekannten Weise auf einen gefundenen Wurm oder dergleichen aufmerksam macht. In diesem Falle handelt es sich nicht um einen Instinkt, ein Entenweibchen hat nämlich nicht die Fähigkeit, ihre Jungen zum Futter heranzulocken, denn es sucht ja niemals für seine Nachkommenschaft etwas Geniefsbares auf. Bei der Henne haben die jungen Enten also wirklich a us Erfahrung gelernt, dafs es auf einen gewissen Ton hin etwas zu fressen gibt.

Im allgemeinen ist die erwachsene Brautente dem Menschen gegenüber wenig scheu und nicht mifstrauisch, man mufs leider sagen, eher zu zahm. Wenn z. B. verschiedene frei fliegende Entenarten auf einem Teiche unseres Zuologischen Gartens liegen, und man kommt mit dem Kahn oder Netz auf die Wasserfläche, so sind die Brautenten gewöhnlich die letzten, welche abstreichen, ja, es gibt einzelne Stücke, die sich überhaupt nicht so leicht dazu entschliefsen, den Teich zu verlassen.

Recht entwickelt ist der Ortssinn: ich glaube, es kommt kaum vor, dafs sich Brautenten verfliegen. Als Bewohner kleiner Waldgewässer wissen sie gerade solche ausgezeichnet in Erinnerung zu behalten und wiederzufinden, ganz im Gegensatz zu manchen anderen Entenarten, die mehr auf grofse Wasserflächen angewiesen sind. Diese verlieren, wenn sie ihren heimischen Teich wegen hoher Bäume aus der Luft nicht mehr sehen können, bisweilen ganz die Orientierung und fliegen schliefslich aufs Geradewohl immer weiter weg, statt umzukehren. Diese Findigkeit im Zurückkehren wird allerdings auch wohl dadurch bedingt, dafs unser Vogel sehr leicht zwischen hohen Bäumen herunterkommen kaun, während Streckenflieger, wie z. B. Peposaca- oder Brandenten, immer nur mit grofsen Wasserflächen als Einfallsmöglichkeiten rechnen und deshalb in flugfähigem Zustande für die Besiedlung kleiner Teiche ungeeignet sind. 
Andererseits „kleben“ Brautenten häufig nur zu sehr an den Teichen, auf denen sie grofs geworden sind. Sie beschränken sich oft nur darauf, einige Rundflüge zu machen oder die allernächsten Gewässer aufzusuchen, und diese Eigenschaft ist ibrer Verbreitung in die weite Umgegend hinderlich; jedoch verhalten sich darin nicht alle Individuen gleich.

Als Intelligenzprüfung glaubte ich namentlich bei Schwimmvögeln ihre Findigkeit im Überfliegen trennender, durchsichtiger Zwischenwände verwerten zu könmen, aber ich bin davon doch mit der Zeit abgekommen. Ist z. B. eine Wasserfläche durch Drahtgeflechte in mehrere Abteilungen geteilt, und gerät eine Ente oder Gans in ein ihr nicht zusagendes Gehege, so wird sie zunächst zurückschwimmen wollen. Sie stöfst dabei an das trennende Gitter und schwimmt nun fortwährend an diesem hin und her, indem sie andauernd versucht, durch dieses hindurchzukommen. Je nach den verschiedenen Zahnschnäbler-Arten dauert dies stunden- oder tagelang. Schliefslich wird dann die trennende Wand überflogen, und das Ziel ist damit erreicht. Man kann mit ein und demselben Vogel diesen Versuch oft wiederholen und wird dabei finden, dafs sich die Zeit, die vergeht, bis der Vogel darauf kommt, das Gitter zu überfliegen, immer mehr verkürzt, bis sie schliefslich fast gleich Null wird. Auch hier ergibt sich ein recht unterschiedliches Verhalten bei den verschiedenen Anseriformes. Im allgemeinen sind Braut-, Mandarinund Türkenenten um den richtigen Ausweg nicht lange verlegen. Viele Gänse, namentlich Schwäne und z. B. Spiefsenten stellen sich dagegen entsetzlich dumm an, hier können wirklich Tage vergehen, bis die Tiere, oft nur durch einen Zufall veranlafst, durch die Luft ihrem Ziele zustreben. Bei näherer Überlegung müssen wir uns aber wohl sagen, dafs solche Vögel, welche sich auch in ihrem Freileben häufig über Hindernisse hinwegbegeben müssen, oder die gewöhnt sind aufzubaumen, überhaupt schon instinktiv an das Überfliegen denken, dagegen werden solche Tiere, welche nicht Hindernissondern Streckenflieger sind, eigentlich nur dann zum Fliegen gereizt, wenn sie eine grofse Fläche vor sich haben oder an eine gröfsere Ortsveränderung denken. Die Punkte, die sie unmittelbar vor sich sehen, können ein Schwan oder eine Spiefsente unter natürlichen Verhältnissen immer schwimmend erreichen, denn in der freien Natur gibt es keine Drahtgeflechte, und auf solche Gewässer, die mit dornigem und für die Tiere undurchdringlichem Gebüsch bestanden sind, die also ein gelegentliches Hindernisfliegen erforderlich machen würden, gehen diese Arten nicht. Eigentümlich für Braut-, Mandarin- und Türkenenten ist, dafs sie beim Überfliegen einer trennenden Drahtwand sich gewöhnlich erst oben auf diese setzen, dort eine Weile halt machen und dann nach der anderen Seite herabfliegen, ganz so, wie wir es z. B. von Haushühnern zu sehen gewohnt sind: auch diese fliegen immer erst auf den Zaun und dann auf der andern Seite hinunter: hier handelt es 
sich also offenbar um einen typischen Waldvogel-Instinkt. Ferner müssen wir bedenken, dafs die drei letzterwähnten Entenformen in ziemlich gerader Richtung vom Wasser aufstehen können, während z. B. ein Schwan, oder bis zu einem gewissen Grade auch eine Spiefsente, sich nur spitzwinklig erheben kann, letztere müssen sich also, um ein Hindernis überfliegen zu können, erst recht weit von diesem wegbegeben. Gerade an diesem Zurückschwimmen scheitert gewöhnlich der Vorsatz des Überfliegens: es will dem Vogel garnicht in den Kopf, dafs er erst nach einer Seite schwimmen soll, die der Richtung, welche er eigentlich einzuschlagen beabsichtigt, genau entgegengesetzt ist, und eine je gröfsere Entfernung von der trennenden Wand dabei nötig wird, um so schwieriger gestaltet sich die Angelegenheit für das Versuchsobjekt. Es würde zu weit führen, hier bei Betrachtung der Brauteite auf diesen an sich interessanten Punkt noch weiter einzugehen, ich möchte nur davor warnen, die Findigkeit eines Waldvogels unmittelbar seiuer Intelligenz zugute zu schreiben, denn es handelt sich hier meist nicht um eine Verwertung von Erfahrungen, sondern um angeborene Instinkte.

\section{Einbürgerung.}

Wenn ich Fachornithologen von meinen Einbürgerungsversuchen mit der Brautente erzählte, so ist mir schon der Einwand gemacht worden, dafs es sich dabei um eine Fälschung der heimischen Fauna handle, und es sei mir deshalb gestattet, auf diese Frage mit ein paar Worten einzugehen. Bekanntlich wird auch die Einführung des Jagdfasans von vielen als eine solche Fälschung angesehen, aber ich glaube, dafs die überwiegende Anzahl der Naturbeobachter und Jäger doch wohl der Ansicht ist, dafs wir in diesem Hühnervogel weniger eine Fälschung als vielmehr eine sehr angenehme Bereicherung unserer heimischen Vogelwelt erfahren haben. Ich glaube, dafs hierbei immer das der leitende Gesichtspunkt sein mufs, ob durch eine Neueinführung andere heimische Tiere verdrängt werden, oder ob die Fremdlinge gewissermafsen einen Platz ausfüllen, für den wir in unserem kultivierten Deutschland von Natur noch keinen Bewohner besitzen.

Auer- und Haselwild können sich nun einmal nicht an bebauten Boden und forstlich intensiv bewirtschaftete Wälder gewöhnen, sie sterben an solchen Orten einfach aus, und an ihrer Stelle kann der Fasan ein ausgezeichnetes Leben führen. Ebenso verhält es sich mit der Brautente. Von unsern deutschen Zahnschnäblern sind der grofse Säger und die Schellente baumhöhlenbrütend, jedoch dabei nicht eigentliche Waldvôgel. Eine Ente, welche kleine Waldgewässer, die ja auch in unsern Parkanlagen meist nachgeahmt werden, bewohnt, besitzen wir nicht, und hierfür ist unsere Nordamerikanerin eine ausgezeichnete Zugabe. Wegen ihrer ganz anderen Lebensbedingungen verdrängt sie keine unserer heimischen Enten, und an ein Erzeugen von Mischlingen mit ihnen in gröfserem 
Mafsstabe ist nicht zu denken. Aufserdem sind solche Hybriden unfruchtbar, denn wie schon erwähnt, steht Lampronessa den bei uns heimischen Entengattungen verwandtschaftlich sehr fern.

Nach meinen bisherigen Beobachtungen eignet sich die Brautente ganz vortrefflich zum wild en Parkvoge l. Sie ist nicht scheu und liebt gerade solche Wasserflächen, wie wir sie künstlich in unsern Parkanlagen herzustellen pflegen, und, wenn sie offenes Wasser hat, denkt sie im Winter nicht daran, nach dem Süden zu ziehen.

Über die Technik der Einbürgerung habe ich bereits im Anfang unserer Betrachtungen verschiedenes erwähnt. Wir wissen, dafs unser Vogel sich auf den genannten Teichen auch ohne menschliches Zutun selbständig vermehren kann und unsere strengsten Winter aushält.

Für die Besiedelung geeigneter Gewässer empfiehlt es sich wohl am meisten, sich zu Ende des Winters einige möglichst blutsfremde Paare zu verschaffen, diese, wenn wegen Raubzeugs u. s. w. nicht anders angängig, in einer verschlossenen Volière mit geeigneten Nistvorrichtungen zu halten und den Tieren die Eier wegzunehmen, um sie von Hühnern ausbrüten zu lassen. Es sei bemerkt, dafs, ihrer Flugfähigkeit beraubte, also amputierte Enten schwerer zur Fortpflanzung schreiten als vollflügelige, sodafs man also in einem Flugkäfig besser züchtet, als wenn man sie flugunfähig in kleinen, oben offenen Gehegen unterbringt. Bei der Verträglichkeit unserer Vögel können unbedenklich mehrere Paare zusammen gehalten werden.

Zum Kennzeichnen der einzelnen Stücke empfehlen sich Fufsringe von $8 \mathrm{~mm}$ Innendurchmesser a us Aluminium oder Celluloid. Erstere können mit Jahreszahl u. s. w. versehen werden, letztere werden in mehreren Farben geliefert, geben also dem Züchter die Möglichkeit, seine Vögel auch ohne sie einzufangen, zu unterscheiden. Irgendwelche Belästigung oder Gefährdung für die. Tiere entsteht durch diese Ringe nicht.

Die Ernährung der Brautente ist dieselbe, wie die aller anderen Wildenten: ein gutes Körnerfutter, ab und zu ein Weichfutter (Spratts Patent), etwas Fleisch, getrocknete Garneelen, die ja jetzt im Handel leicht zu haben sind, Grünzeug aller Art, Eicheln u. s. w. entsprechen allen ihren Anforderungen.

Über die Güte des Wildbrets möchte ich, trotzdem ich es gelegentlich der Wissenschaft halber gut gebraten verzehrt habe, kein abschliefsendes Urteil abgeben, da auch freifliegende Parkenten sich so an das vom Menschen gereichte Futter halten, dafs ein charakteristischer Wildgeschmack nicht recht zu stande kommt. Im Herbst besonders sind unsere Brautenten sehr fett und jüngere Stücke recht zart.

Geeignete Bezugsquellen für unsern Vogel ergeben sich bei Durchsicht des Anzeigenteils der Fach-, besonders der Geflügelzeitungen. Gegenwärtig stellt sich der Preis eines Paares je nach Herbst oder Frühjahr auf etwa 28 bis 40 Mark. 
Jetzt zu Ende des Jahres 1909 dürften sich auf den Gewässern unseres Berliner Zoologischen Gartens und seiner Umgebung schätzungsweise 120 Stück umhertreiben. Eine genaue Zählung läfst sich jedoch erst nach dem Eintritt strengen Frostes, wenn sich die Tiere auf die wenigen eisfreien Stellen zusammengezogen haben, ermöglichen.

Um unsere Enten auch an Ausflüge nach anderen Parkanlagen zu gewöhnen, sandte ich im Sommer 6 noch nicht ganz flugfähige Junge nach dem $4 \mathrm{~km}$ entfernten Charlottenburger Schlofspark. Gerade während ich nun mein Manuskript zum Abschlufs bringe, schreibt mir der dortige Kgl. Obergärtner, Herr Buttmann, unter dem 4.11.09. wörtlich folgendes:

„Der Lieblingsaufenthalt der 6 Enten am Tage ist der Graben hinter dem Mausoleum, wo ein grofser Acer saccharinum seine Äste über den Wasserspiegel breitet. Die Enten sitzen entweder auf den überhängenden Ästen, oder sie schwimmen zwischen den teils in's Wasser hängenden Zweigen lustig umher.

Wenn die Dämmerung kommt, fliegen sie gewöhnlich mit lautem „Hi hi“ auf unseren grofsen Teich, an dessen Rande Eichen stehen und tauchen nach hineingefallenen Eicheln. Am Tage sind sie fast nie auf dem grofsen Teich zu finden, sondern immer auf ihrem vorher angegebenen Lieblingsplatz.

Mit den Stockenten haben sie keine Gemeinschaft, wohl aber erhalten sie häufig Besuch anderer Brautenten, sodafs ich neulich 24 Stück zählte. Stellt man sich längere Zeit hin, namentlich gegen Abend, und beobachtet die ganze Gesellschaft fortwährend, so erhebt sich plötzlich der Besuch in die Lüfte, während unsere 6 ruhig auf dem Wasser bleiben, ein Zeichen ihrer grofsen Zahmheit, die man in der Weise bei der Stockente nicht findet.

Seit einigen Tagen hat sich nun den Brautenten ein anderer Besuch zugesellt". (Nämlich Mandarinenten.)

Nicht nur bei unsern Berliner Brautenten, sondern auch bei denen anderer Züchter hat sich herausgestellt, dafs sich in vielen Gelegen leider ein grofser Prozentsatz unbefruchteter oder in den ersten Entwicklungstagen absterbender Eier befindet. Die Ursache dieses Mifsstandes ist mir nicht recht klar, an der Art des Nestes, starker Kälte, Hitze oder Trockenheit während des Legens und Brütens kann es nicht liegen, denn man findet zu derselben Zeit unter fast absolut gleichen Nestverhältnissen auch vollkommen gute Gelege, in denen alle Eier zur normalen Entwicklung gelangen. Ich hatte in diesem Jahre den Verdacht, dafs das schlechte Befruchtungsverhältnis in der grofsen Anzahl von Erpeln begründet sei, die wir dieses Jahr batten, zumal ich öfter beobachtete, dâfs die einzelnen Paare im Treten durch aufdringliche Nebenbuhler gestört wurden. Aber dieser Grund ist nicht stichhaltig, denn auch ein befreundeter Züchter, bei dessen Enten das Geschlechtsverhältnis ein richtiges war, fand 
ebensoviele unbefruchtete Eier. Auch dem Umstande, dafs unsere Parkenten im Herbst ungemein fett werden und ihren nur $\mathrm{zu}$ guten Ernährungszustand bis zum Frühling hin bewabren, habe ich Schuld gegeben. Wenn man aber bedenkt, dafs auch die letzte Brut, also sogar das 3. Gelege einer Ente manchmal dasselbe schlechte Resultat ergibt, so mufs man wohl zu der Überzeugung kommen, dafs auch der Fettansatz nicht schuld sein kann, denn gegen den Sommer hin sind sowohl Erpel als Enten doch allmählich magerer geworden: das Gewicht der ersteren ist dann von $890 \mathrm{~g}$ auf $690 \mathrm{~g}$ herabgegangen.

Die Hauptursache schlechter Befruchtung ist wohl die allmählich eintretende Inzucht: sämtliche in Deutschland befindliche Brautenten stammen nur von wenigen importierten Paaren ab, und, da die Ausfuhr aus den Vereinigten Staten von den Amerikanern sehr streng verboten ist, so haben wir seit über einem Jahrzehnt kein frisches Blut mehr erhalten können. Natürlich lassen es sich alle Züchter und auch ich selbst sehr angelegen sein, innerhalb Deutschlands recht oft einen Blutswechsel unter den Brautentenstämmen vorzunehmen, aber es scheint, dafs diese Mafsnahme heute doch nicht mehr genügt. Eine Neueinfuhr von wenigstens einigen Paaren aus Nord-Amerika wäre daher sehr erw ünscht.

\section{Schutz.}

Nicht nur ich selbst, sondern auch verschiedene andere Interessenten - und es gibt deren glücklicherweise bereits eine ganze Anzahl in unserer Heimat - haben die schmerzliche Erfahrung gemacht, dafs Brautenten, welche sich von ihren Wohngewässern in die Umgegend verbreiten, dort den Jägern zum Opfer fallen. Trotzdem in verschiedenen Jagdzeitungen bereits Aufsätze über unsere Enten erschienen sind, scheint die Kenntnis dieser Art in den weiteren Jägerkreisen doch noch sehr im arge zuliegen, und offen gesagt, ist dies auch kein Wunder, denn sehr viele unserer Nimrode kennen ja nicht einmal unsere heimischen Enten, selbst dann nicht, wenn es sich um Erpel im Prachtkleide handelt, also um ganz typische Exemplare, die man leicht nach jedem Naturgeschichtsbuch bestimmen kann! Ich nehme es keinem übel, dafs er seine Brautenten amputiert oder einsperrt, wenn von den abendlichen Streifzügen immer weniger der bunten Vögel zurückkehren, und in den beteiligten Kreisen sehnt man sich daher mit Recht sehr nach einem gänzlichen Schutz unseres Vogels. Am zweckmäfsigsten wäre es, der Brautente vorläufig eine dauernde Schonzeit zu gewähren, nur so könnte an ihre weitere Einbürgerung in Deutschland mit Erfolg herangegangen werden. Natürlich verüble ich es keinem Schützen, wenn er bei dem abendlichen Entenanstand eine zufällig vorüberstreichende Lampronessa herunterholt, denn das sichere Ansprechen dieser Art im Fluge erfordert viel Übung. Gegen 
solche „fahrlässige Tötung“ soll das Gesetz natürlich nicht schützen, wohl aber gegen wirklich vorsätzlichen "Mord“. Der schwimmende Brauterpel ist ein so auffallender und so leicht kenntlicher Vogel, dafs an ein Verwechseln mit irgend einer heimischen Entenart nicht zu denken ist, selbst mit den nordischen, seltener nach Deutschland geratenden Anatiden hat er keinerlei Ähnlicbkeit: ein Blick auf die beigegebenen Abbildungen belehrt auch den Uneingeweihtesten vollkommen über die Artzugehörigkeit eines solchen Vogels.

Ich brauche wohl nicht hervorzuheben, dafs von irgend welchem durch die Brautente angerichteten Schaden ebensowenig die Rede sein kann, wie bei den andern kleineren Entenarten. Auf Fischzuchtgewässer gehört sie natürlich nicht, im übrigen ist sie aber in jeder Weise harmlos und auch mit andern Zahnschnäblern durchaus verträglich.

\section{Beschreibung.}

Prachtkleid des Männchens: (Kennzeichen) Oberseite im wesentlichen schwarz, auf dem Kopf mit grünem und purpurnem, auf dem Oberrücken mit bronzenem und weiter nach hinten mit stahlblauem Glanz. Unterseite weifs, nur Vorderhals und Kropf tief kastanienbraun mit kleinen, dreieckigen, weifsen Punkten, Unterschwanzdecken braunschwarz. An den Kopf-, Brust- und Bauchseiten eine sehr hervortretende weifse Zeichnung.

Die Haube, welche von der Stirn aus den ganzen Oberkopf einnimmt und weit im Nacken herunterhängt, ist im wesentlichen grünglänzend. Ein sehr feiner, von der oberen einspringenden Schnabelecke beginnender Streifen, der sich als Augenbrauenstrich nach hinten fortsetzt, sowie ein etwas breiterer, dem vorigen fast gleichlaufender, hinter dem Auge nach der Haubenspitze ziehender Strich sind weifs, sie lassen zwischen sich ein purpurglänzendes Band. Die Gegend vor dem Auge glänzt dunkelgrünlich, unter demselben ist ein purpurviolett glänzendes Feld, ebenso ist die hintere Kopfseite gefärbt. Kinn, Kehle, Vorderhals und ein breites Halsband, das sich nach hinten und oben verjüngt, sind rein weifs, ebenso ein sehr markanter Strich von der Kehle hinauf nach der Ohrgegend. Hinterhals, und Oberrücken sind dunkelolivbraun, zum Teil mit bronzefarbigem Schiller. Der untere Teil des Vorderhalses und die Kropfgegend bis zu den Schultern sind kastanienbraun. Genau auf dem Kropf trägt jede Feder an ihrer Spitze einen weifsen dreieckigen Fleck, die Gröfse dieser Flecke nimmt nach der Mitte und nach unten hin zu, an den äufseren Kropfseiten und der Schultergegend fehlen sie ganz. Brustmitte und Bauch sind rein weifs, die Federn nach der Kropfgegend und den Seiten hin zum Teil dunkel gebändert. Den Vorderrand der Brustseite bildet ein weifser, zur Körperachse des Vogels beinahe rechtwinklig stehender, nach hinten von einem 
schwarzen Band begrenzter Streifen, welcher den rotbraunen Kropf abschliefst. Die an den Brustseiten stehenden Tragfedern sind hellgelblich, fein schwarz gewässert, die längsten tragen an ihrer sehr breiten Spitze abgesetzt schwarz-weifse Querbänder und stellen sich am lebenden Vogel in der Ruhelage so, dafs durch ibre Spitzen ein scharfes, schwarz und weifses Band gebildet wird, welches längs an der Körperseite hinzieht und schliefslich etwa $4 \mathrm{~cm}$ vor dem Schwanzansatz mit einer Rundung nach unten verläuft. Unterschwanzdecken durkelbraun, ein etwa $2,5 \mathrm{~cm}$ breites Feld zwischen letzteren und dem hinteren Tragfederrande dunkelpurpurviolett, nach hinten oben begrenzt durch einige, etwas über dem Schwanzansatz entspringende und nach unten über die Basis der äufseren Steuerfedern herabfallende haarartige, orangegelbe Federn. Handschwingen dunkelbraun, Spitzendrittel der Aufsenfahne der längsten Schwingen glänzend silberweifs, das bei den inneren Handschwingen sich allmählich verliert. Innenfahne graubraun, die Spitzen, soweit sie im zusammengelegten Flügel sichtbar sind, glänzend dunkelblau. Die 9 äufseren Armschwingen sind an ihrer Aufsenfahne stahlblauglänzend und quer über die ganze Spitze zieht sich ein $2-3 \mathrm{~mm}$ breites weifses Band, welches von dem blauen Teil durch einen schmalen, schwarzen Strich getrennt wird. Bei den 3-4 äufsersten Armschwingen ist der Glanz weniger entwickelt und das weifse Band etwas breiter. Die 10. Armschwinge (von aufsen gerechnet) ist anders geformt und trägt an dem gröfsten Teil der Aufsenfahne einen prachtvollen, bronze- bis messingfarbenen Glanz. Die dann folgende, auf $41 \mathrm{~mm}$ verbreiterte Feder ist tiefsamtschwarz mit weifsem Spitzenquerband, an dessen Ende sich noch ein schmaler, schwarzer Saum vorfindet. Die innerste Armschwinge endlich sowie die folgenden Ellbogenfedern sind glänzend blauschwarz. Alle kleinen Oberflügeldecken, sowie die grofsen Deckfedern der Hand- und der äufseren Armschwingen dunkelgraubraun, die grofsen Deckfedern der inneren Armschwingen stahlblauglänzend mit schmalem, schwarzem Endrand. Die kleinen Unterflügeldecken sowie ein grofser Teil der grofsen Unterflügeldecken sind weifs und schwarzbraun quergebändert (gesperbert). Der Schnabel ist vierfarbig: ein schmaler Rand um die Basis der einspringenden Ecken des Oberschnabels ist gelb, dann folgt eine im Mittel $18 \mathrm{~mm}$ breite dunkelkarminrote Zone, die den Raum bis fast zu den Nasenlöchern einnimmt, und sich als schmaler Rand an den Schnabelseiten nach vorn hinzieht. Zwischen den Nasenlöchern befindet sich ein etwa $2^{1 / 2} \mathrm{~cm}$ langer, von einer weifslichen, im Durchschnitt $4 \mathrm{~mm}$ breiten Zone umgebener schwarzer Fleck, desgleichen sind die Schnabelspitze und der Unterschnabel schwarz. Die Füfse sind olivengelb, die Schwimmhäute und die Rückseite des Laufs schwärzlich. Das recht grofse Auge ist leuchtend karminrot, ein schmaler sich nach vorn etwas verbreiternder Lidrand ebenso. 
Die Länge beträgt $450-485 \mathrm{~mm}$, der Flügel mifst $230-235$, der Schwanz 125, die Breite 730-745, der Schnabel $35 \mathrm{~mm}$. Recht fette Brauterpel wiegen bis $890 \mathrm{~g}$ (Herbstgewicht), im Juni werden sie um 200 g leichter.

Das alte W eibchen ist im allgemeinen graubraun gefärbt, die Oberseite zeigt in der Rückengegend, die im wesentlichen durch die Schulterfedern gebildet wird, einen bronzefarbenen Glanz, und die einzelnen Federn tragen dort feine schwarze Endsäume. Um die Schnabelbasis verläuft eine weifse Linie, Kinn, Kehle und der oberste Teil des Vorderhalses sind gleichfalls weifs, ebenso ein Ring um das Auge, der sich nach hinten verbreitert und als feine Linie an der Kopfseite auslaufend den Ansatz der kleinen Haube nach unten abgrenzt. Unterbrust und Bauch sind weifslich, die Kropf- und Seitenfedern bräunlich, erstere mit schmalen, letztere mit sehr breiten geblichen Längsflecken geziert. Die Handschwingen und ihre kleinen Deckfedern, sowie die kleinen Deckfedern des Unterarmes gleichen fast ganz denen des Erpels, nur ist der weifse Aufsensaum der äufseren Handschwingen und der Glanz an der Spitze der Innenfahne etwas weniger entwickelt. Der Spiegel unterscheidet sich von dem des Männchens dadurch, dafs er nicht durch einen schmalen weifsen Rand, sondern durch etwa $8 \mathrm{~mm}$ breite weifse Spitzenflecke begrenzt wird, die sich nur wenig auf die Innenfahne ausbreiten. Der 10. Armschwinge fehlt, wie der 10. des Männchens, der weifse Endfleck, dagegen trägt ihre Aufsenfahne im Gegensatz zur „Messingfeder" des Erpels einen tiefschwarzen Längsstreifen. Die folgenden Armschwingen sind braun mit bronzefarbenem Schimmer und angedeutetem schwarzen Endrand. Sehr prächtig sind die grofsen Deckfedern der inneren Armschwingen: ibre Grundfarbe ist ein satter, blauer Stahlglanz, im Enddrittel jedoch macht dieser einem leuchtenden, violetten Schimmer Platz, ihr Ende ist samtschwarz gerandet.

Der Schnabel ist schwarz, die Füfse sind dunkler als beim Erpel gefärbt, nämlich olivgrünlich, Auge dunkelbrạn, Lidrand leuchtend gelb.

Länge etwa 450, Flügel 230, Schwanz 103, Breite 715, Abstand der Flügel- und Schwanzspitze $45 \mathrm{~mm}$. Das Gewicht gut fetter Weibchen ist etwa $630-650 \mathrm{~g}$, bei vollkommen abgezehrten kann es bis auf $350 \mathrm{~g}$ herabgehen.

Das Sommerkleid des Erpels ist ziemlich einfarbig dunkelgraubraun, die Oberseite weist etwas Glanz auf, und die weifse Zeichnung an Kopf und Hals entspricht ziemlich genau der des Prachtkleides, die Haube fehlt. Das ganze Gefieder unterscheidet sich von dem Weibchenkleid durch das vollkommene Fehlen der für dieses charakteristischen weifsgelben Brust- und Seitenzeichnung, sowie durch das Vorhandensein der auch in diesem Kleidesehr auffallenden weifsen Erpel-Kopfzeichnung. Der Schnabel und das Rot des Auges sind matter gefärbt als im Prachtkleide. 
Das Jugendkleid des Erpels ähnelt sehr dem Sommerkleid des alten Vogels, nur ist die weifse Kopf- und Halszeichnung viel weniger ausgebildet und eine helle Strichlung in der Kropfgegend und an den Seiten deutlich erkennbar; auch ist der Schnabel bei recht jungen Tieren noch schwarz und das Auge dunkelbraun.

Das Jugendkleid des Weibchens unterscheidet sich von dem Alterskleid dadurch, dafs es noch die weifse Linie um die Schnabelbasis und die weifse „Brille“ vermissen läfst, dagegen zieht je eine helle, der weifsen Haubenzeichnung des ErpelPrachtkleides entsprechende Linie vom oberen und unteren Augenrand nach hinten. Die Seitenfedern (Tragfedern) sowie das Kropfgefieder sind nicht so lebhaft längsgestreift als bei der alten Ente, aber deutlicher als beim jungen Männchen.

Das Dunenkleid ist oberseits dunkelolivenbraun, die Unterseite gelblich weifs, also nicht gelb, wie bei vielen anderen jungen Enten, z. B. Stockenten. Am Kopf beschränkt sich die dunkle Farbe auf die Oberseite und eine Linie, welche vom Auge nach hinten an den Kopfseiten entlang geht, aufserdem befinden sich in der Ohrgegend noch einige dunkle Stellen. Auf dem Rücken sind dieselben hellen Flecke vorhanden, wie bei den meisten andern Entenarten auch, d. h. jederseits am Ansatz der Oberschenkel und in der Gegend des Flügelansatzes, jedoch sind auch diese Flecke nicht gelb, sondern fast weifslich. Der Schnabel ist schwarz, das Auge dunkelbraun, die Schwimmhäute, Zehengelenke und die Rückseite des Laufs sind schwärzlich, das Übrige grünlichgrau.

Das Gewicht einige Stunden alter Brautenten beträgt 20-24 g. 


\section{$2 \mathrm{BHL}$ Biodiversity Heritage Library}

1910. "Beobachtungen bei einem Einbürgerungsversuch mit der Brautente (Lampronessa sponsa (L.))." Journal $f u$

r Ornithologie 58, 101-156. https://doi.org/10.1007/bf02094957.

View This Item Online: $\underline{\text { https://www.biodiversitylibrary.org/item/43496 }}$

DOI: https://doi.org/10.1007/bf02094957

Permalink: https://www.biodiversitylibrary.org/partpdf/142690

\section{Holding Institution}

MBLWHOI Library

\section{Sponsored by}

MBLWHOI Library

\section{Copyright \& Reuse}

Copyright Status: No known copyright restrictions as determined by scanning institution.

This document was created from content at the Biodiversity Heritage Library, the world's largest open access digital library for biodiversity literature and archives. Visit BHL at https://www.biodiversitylibrary.org. 